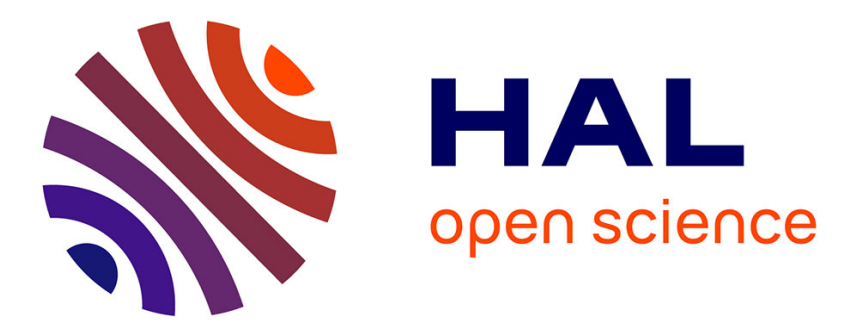

\title{
Granular mixture deflation and generation of pore fluid pressure at the impact zone of a pyroclastic fountain: Experimental insights
}

\author{
Allan Fries, Olivier Roche, Guillaume Carazzo
}

\section{To cite this version:}

Allan Fries, Olivier Roche, Guillaume Carazzo. Granular mixture deflation and generation of pore fluid pressure at the impact zone of a pyroclastic fountain: Experimental insights. Journal of Volcanology and Geothermal Research, 2021, 414, pp.107226. 10.1016/j.jvolgeores.2021.107226 . hal-03254051

\author{
HAL Id: hal-03254051 \\ https://hal.uca.fr/hal-03254051
}

Submitted on 23 Jun 2021

HAL is a multi-disciplinary open access archive for the deposit and dissemination of scientific research documents, whether they are published or not. The documents may come from teaching and research institutions in France or abroad, or from public or private research centers.
L'archive ouverte pluridisciplinaire HAL, est destinée au dépôt et à la diffusion de documents scientifiques de niveau recherche, publiés ou non, émanant des établissements d'enseignement et de recherche français ou étrangers, des laboratoires publics ou privés.

\section{(c)(1)}

Distributed under a Creative Commons Attribution| 4.0 International License 


\title{
Granular mixture deflation and generation of pore fluid pressure at the impact zone of a pyroclastic fountain: experimental insights
}

\author{
Allan Fries ${ }^{1,2 *}$, Olivier Roche ${ }^{1}$, Guillaume Carazzo ${ }^{3}$ \\ ${ }^{1}$ Université Clermont Auvergne, CNRS, IRD, OPGC, Laboratoire Magmas et Volcans, F- \\ 63000 Clermont-Ferrand, France. \\ ${ }^{2}$ Université de Genève, Département des Sciences de la Terre, rue des Maraîchers 13, 1205 \\ Genève, Suisse. \\ ${ }^{3}$ Université de Paris, Institut de Physique du Globe de Paris, CNRS, F-75005 Paris, France. \\ * Corresponding author: Allan Fries, allan.fries@unige.ch
}

\section{Highlights}

- We present analogue experiments on pyroclastic fountain collapse

- We release glass beads from a hopper at different heights above a horizontal channel

- Stokes number $\sim 10^{-3}-10^{1}$ corresponds to $0.1-1 \mathrm{~mm}$ sized particles in nature

- Pore fluid pressure measured at impact is high enough to cause partial fluidization

- The runout distance of the dense flow formed upon impact scales with the fall height

\begin{abstract}
We present the results of analogue laboratory experiments on pyroclastic fountain collapse. Mixtures of air and glass beads ranging in size around $75 \pm 15 \mu \mathrm{m}$, with Stokes number of $10^{-3}-10^{1}$ and representative of $0.1-1 \mathrm{~mm}$ sized particles in nature, were released from a hopper at heights of 0.45-2.95 $\mathrm{m}$ above the base of a horizontal channel. Free fall caused continuous dilation of the granular material and led to mean particle concentrations of $\sim 9-36$ vol. \%, with concentration inversely proportional to drop height, before the particles impacted the channel base. Decoupling between the particles and the ambient air upon impact caused deflation of the mixture, which then propagated laterally as a dense granular flow overridden by a dilute suspension. Measurements at the impingement surface revealed that pore fluid pressure, generated through high air-particle relative velocity during deflation, counterbalanced up to $50 \%$ of the weight of the emerging granular flow. The runout distance of the dense flow increased linearly with the fall height, similar to published results on unidirectional flows generated from collapse of packed granular columns. This suggests that the runout of flows resulting from release of granular material is controlled essentially by conversion of potential to kinetic energy and that the initial particle concentration is a second order parameter. We conclude that fountaining of pyroclastic material containing large amounts of particles with Stokes numbers of the order $10^{-3}-10^{1}$ can generate dense pyroclastic flows with some degree of pore fluid pressure.
\end{abstract}

Keywords. pyroclastic fountain; pyroclastic flow; experiment; pore fluid pressure; Stokes number 


\section{List of symbols}

\begin{tabular}{|c|c|c|}
\hline Notation & & Units \\
\hline$d$ & particle diameter & $\mathrm{m}$ \\
\hline$g$ & gravitational acceleration & $\mathrm{m} \mathrm{s}^{-2}$ \\
\hline$g^{\prime}$ & reduced gravity & $\mathrm{m} \mathrm{s}^{-2}$ \\
\hline $\boldsymbol{h}$ & flow thickness & $\mathrm{m}$ \\
\hline $\boldsymbol{h}_{\boldsymbol{b}}$ & height of the granular bed & $\mathrm{m}$ \\
\hline$m$ & granular mass & $\mathrm{kg}$ \\
\hline$t$ & time after impact & s \\
\hline$t_{f}$ & time of flow emplacement & s \\
\hline$t_{r}$ & duration of particle release & $\mathrm{s}$ \\
\hline $\boldsymbol{A}$ & area of hopper aperture & $\mathrm{m}^{2}$ \\
\hline C & particle concentration of the dense granular bed & - \\
\hline$C_{i}$ & particle concentration of the granular mixture at impact & - \\
\hline $\boldsymbol{H}$ & drop height & $\mathrm{m}$ \\
\hline $\boldsymbol{L}$ & maximum runout distance & $\mathrm{m}$ \\
\hline$\dot{M}$ & particle mass flux & $\mathrm{kg} \mathrm{s}^{-1}$ \\
\hline $\boldsymbol{P}$ & pore fluid pressure & $\mathrm{Pa}$ \\
\hline$P_{L}$ & lithostatic pressure & $\mathrm{Pa}$ \\
\hline $\boldsymbol{R}$ & radius of the impact zone & $\mathrm{m}$ \\
\hline $\boldsymbol{U}$ & characteristic fall velocity of the mixture & $\mathrm{m} \mathrm{s}^{-1}$ \\
\hline$U_{f}$ & interstitial air velocity & $\mathrm{m} \mathrm{s}^{-1}$ \\
\hline $\boldsymbol{U}_{\boldsymbol{i}}^{\prime}$ & mixture velocity at impact & $\mathrm{m} \mathrm{s}^{-1}$ \\
\hline$U_{s}$ & superficial air velocity & $\mathrm{m} \mathrm{s}^{-1}$ \\
\hline$V_{f}$ & flow velocity & $\mathrm{m} \mathrm{s}^{-1}$ \\
\hline$V_{s}^{\prime}$ & particle settling velocity & $\mathrm{m} \mathrm{s}^{-1}$ \\
\hline$\gamma$ & flow shear rate & $\mathrm{s}^{-1}$ \\
\hline$\varepsilon_{p}$ & particle volume fraction & - \\
\hline$\kappa$ & hydraulic permeability & $\mathrm{m}^{2}$ \\
\hline$\lambda$ & deposit aspect ratio & - \\
\hline $\boldsymbol{\mu}$ & dynamic viscosity of air & Pa s \\
\hline$\mu_{m}$ & dynamic viscosity of the gas-particle mixture & $\mathrm{Pas}$ \\
\hline $\boldsymbol{\rho}$ & mixture density & $\mathrm{kg} \mathrm{m}^{-3}$ \\
\hline$\rho_{a}$ & ambient density & $\mathrm{kg} \mathrm{m}^{-3}$ \\
\hline$\rho_{p}$ & particle density & $\mathrm{kg} \mathrm{m}^{-3}$ \\
\hline $\mathbf{B a}$ & Bagnold number & - \\
\hline Da & Darcy number & - \\
\hline $\mathbf{R e}$ & Reynolds number & - \\
\hline $\mathbf{R i}$ & Richardson number & - \\
\hline Sa & Savage number & - \\
\hline $\mathbf{S t}$ & Stokes number & - \\
\hline $\boldsymbol{\Sigma}$ & Stability number & - \\
\hline
\end{tabular}




\section{Introduction}

Pyroclastic fountaining occurs when an eruptive mixture of hot pyroclasts and volcanic gas does not entrain and heat enough ambient air to form a buoyant plume and remains denser than the ambient atmosphere (Michaud-Dubuy et al., 2018; Sparks and Wilson, 1976; Woods, 1988). In this eruptive regime, the pyroclastic mixture ejected from the vent reaches a maximum fountain height and collapses under the influence of gravity once its initial momentum is exhausted. The accumulation of the mixture at the impact zone on the ground generates pyroclastic flows that spread radially from the vent (Druitt and Sparks, 1982; Valentine and Wohletz, 1989) and represent a severe natural hazard (Baxter et al., 2017, 2005; Doocy et al., 2013). Sustained fountaining is also called "boiling over" in the literature and has been suggested to operate during single vent as well as ring fracture eruptions. In the latter case, sustained fountaining associated with caldera collapse is thought to generate voluminous pyroclastic flows that travel more than $50-100 \mathrm{~km}$ and form widespread ignimbrites (Cas et al., 2011; Guzmán et al., 2020; Pacheco-Hoyos et al., 2018; Roche et al., 2016). Several issues related to pyroclastic fountaining are yet poorly known. These include in particular the mechanisms of the pyroclastic mixture deflation at the impact zone and the formation of the emerging lateral flows. Recent numerical simulations, however, reveal that the dynamics of the impinging fountain and of the resulting lateral flows depend fundamentally on the degree of gas-particle coupling, which controls the particle size segregation and the flow solid concentration (Breard et al., 2019; Sweeney and Valentine, 2017; Valentine, 2020), and on the velocity of the falling mixture, so that shocks and overpressured lateral jets form in supersonic conditions (Valentine and Sweeney, 2018). Rapid differential motion between the gas and the particles and associated drag force can generate interstitial pore fluid pressure (Breard et al., 2018; Valentine, 2020).

The present contribution addresses the generation of pyroclastic flows by fountaining through experiments on gravitational collapse of granular mixtures in air. Earlier experimental studies in this configuration involving small- or large-scale devices revealed some key aspects. Dellino et al. $(2007,2010)$ showed in 3D experiments that gas-particle mixtures, ejected from a subvertical conduit as a compressed gas was suddenly released into pyroclastic (ignimbritic) material, collapsed when the initial energy in the system was relatively low. The mixtures then accumulated on the ground to form a basal flow overridden by an expanded fully turbulent current. Further experiments were carried out in a channel configuration and addressed in particular the internal flow dynamics and structure. Rowley et al. (2014) released mixtures of air and glass beads ranging in size around $75 \pm 15 \mu \mathrm{m}$ onto the base of a horizontal channel from a hopper positioned at constant height, by controlling the particle mass flux and concentration ( 3-45 vol. \%) at the impact zone depending on the hopper aperture. Lube et al. (2015) and Breard and Lube (2017) used a hopper to release pyroclastic material onto the base of a channel inclined at $5-25^{\circ}$, and the particle concentration at the impact zone ( 0.5-18.5 vol. \%) was obtained by varying the height of the hopper and by controlling the particle flux at the hopper base using an aeration system or obstructing solid structures. A notable feature of the experiments of Rowley et al. (2014), Lube et al. (2015) and Breard and Lube (2017) was that even at the lowest initial particle concentrations of the order of $\sim 1 \mathrm{vol}$. \% the particles accumulated at the impact zone to form a well-developed highly concentrated granular flow. Breard and Lube (2017) showed that with a pyroclastic material, this granular flow had a particle concentration of $\sim 45$ vol. $\%$ and was overridden by a dilute turbulent cloud with particle concentration less than $\sim 1$ vol. $\%$. 
The aim of our study is to examine further in analogue experiments the process of particle accumulation at the impact zone and the mechanisms of formation of the lateral flow. We address in particular the issue of pore fluid pressure generation, which may occur as rapid deflation of the collapsing granular mixture causes significant differential motion between the settling particles and the ambient air (Breard et al., 2018; Valentine, 2020). We also discuss the parameters that control the runout distance of the dense flows generated by granular fountaining.

\section{Experimental methods}

\subsection{Experimental apparatus and procedure}

The experimental apparatus was composed of a 15-liter hopper on top of a vertical open column connected to a horizontal channel (Figure 1). The hopper was the same as the one used by Rowley et al. (2014). It had a longitudinal aperture of $20 \mathrm{~cm}$ and it was fixed on a rigid vertical bar so that the lock-gate system was set at different heights above the channel base ranging from 0.45 to $2.95 \mathrm{~m}$ (Table 1). The vertical column consisted of rigid plastic sheets forming the back and the side walls, with an open front, and whose length was adjusted according to the height of the hopper above the channel. The channel was $3.7 \mathrm{~m}$ long and had $30 \mathrm{~cm}$ high Perspex sidewalls, with smooth porous plates at its base. The base of the hopper, the column and the channel were $10 \mathrm{~cm}$ across. Experiments were recorded at 250-1000 frames per second using a high-speed Photron Fastcam SA3 video camera, either filming a $28 \mathrm{~cm}$-long and $38 \mathrm{~cm}$-high section of the impact zone with a pixel resolution of $0.37 \mathrm{~mm}$ per pixel, or a $175 \mathrm{~cm}$-long and $44 \mathrm{~cm}$-high section of the channel (including the impact zone) at a resolution of $1.7 \mathrm{~mm}$ per pixel.

Measuring pore fluid pressure at impingement was the main objective of this study. We used two piezoresistive sensors provided by ICSensors $^{\text {TM }}$ (model 154N), which measured pressure in the range $\pm 6.9 \mathrm{kPa}$ at frequencies of $100-500 \mathrm{~Hz}$. We placed one sensor at each sidewall of the channel to document the pore fluid pressure at the impact zone. The two sensors were located as close as possible to the impingement point at the lowermost position, $5 \mathrm{~cm}$ from the back-wall of the channel and $1.6 \mathrm{~cm}$ above its base. Following Weit et al. (2018), we set the sensors in casings covered with metallic grids of $30 \mu \mathrm{m}$-aperture, which allowed for transmission of the air to the membrane of the sensors while preventing contact with the particles. In order to correlate pressure data and video recording during subsequent analysis, both measurements were synchronized with an auxiliary trigger that indicated the start of video acquisition by sending a $100 \mathrm{mV}$ pulse to the pressure sensors.

The procedure for running an experiment was the following. The hopper was fixed at a given height and filled with $12 \mathrm{~kg}$ of glass beads with a mean diameter of $75 \pm 15 \mu \mathrm{m}$ and a density of $\sim 2500 \mathrm{~kg} \mathrm{~m}^{-3}$. The high-speed camera was placed either at the impact zone or at downstream positions along the flume, and video recording and pressure measurement were initiated. The lock-gate of the hopper was manually opened rapidly in 0.20 to $0.30 \mathrm{~s}$. Following hopper opening, particles fell vertically through the shrouded column section. After impact with the channel, 1-3 m-long currents formed, which comprised a lower dense flow overridden by a more dilute suspension. The total duration of an experiment was typically $\sim 1-2 \mathrm{~s}$ after gate opening. At the end of an experiment, we measured the thickness of the deposit every $30 \mathrm{~cm}$ from the back-wall of the flume using a ruler. The videos were subsequently analysed with ImageJ ${ }^{\circledR}$ (Schneider et al., 2012) in order to enhance the contrast between the particles and the background before manually tracking the top of the granular bed in the impact zone or the front of the granular flow. We carried out 43 experiments at six different fall heights, with at least six runs per height to ensure for reproducibility of the results (Table 1). 


\subsection{Particle supply from the hopper}

The mass flux of particles released from the hopper was calibrated according to the procedure of Rowley et al. (2014). The hopper was fixed at various heights and the settling particles accumulated into a container on a weight scale, which recorded the mass of particles at a frequency of $25 \mathrm{~Hz}$ and with a precision of $0.1 \mathrm{~g}$. Because the particles had some velocity at impact, the scale designed for static configurations measured an apparent mass in three steps. During particle release, the scale first measured an increase in mass up to a maximum value followed by a decrease in mass corresponding to the scale response time, and finally a constant mass plateau. Therefore, we determined the time-averaged mass flux from the time at which the initial mass in the hopper was recovered (Figure 2). A mass of $12 \mathrm{~kg}$ of particles in the hopper was used for each test and the measurements were repeated 27 times to check for reproducibility. As described in detail hereafter, the granular mixtures accelerated from the exit of the hopper and hence dilated until they reached the impingement surface at the base of the column.

The mean particle concentration of the mixture impacting the weight scale, $C_{i}$, was estimated as

$$
C_{i}=\frac{\dot{M} t_{r}}{H A \rho_{p}},
$$

with $\dot{M}$ the time-averaged mass flux of particles, $t_{r}$ the duration of particle release, $H$ the height of the hopper, $A=0.02 \mathrm{~m}^{2}$ the area of the hopper aperture and impact area, and $\rho_{p}=2500 \mathrm{~kg}$ $\mathrm{m}^{-3}$ the particle density (Rowley et al., 2014). Figure 2 shows that the total duration of particle release plus scale response time (i.e. the time necessary to measure a mass of $12 \mathrm{~kg}$ ) is independent of the fall height and equals $\sim 0.8 \mathrm{~s}$, with the time-averaged mass flux being $\sim 15$ $\mathrm{kg} \mathrm{s}^{-1}$. This demonstrates that the procedure used in our experiments to open the hopper and release the particles is well controlled and reproducible, providing a constant mass flux, as suggested by the linearity of the mass increase during particle release (Figure 2). Moreover, as the mass of particles was constant (i.e. $12 \mathrm{~kg}$ ) in all calibration tests and experimental runs, replacing variables in equation 1 by their values gives a simple relationship where the mean particle concentration decreases as the fall height increases, such as

$$
C_{i}=\frac{0.24}{H} \text {. }
$$

In our experiments $C_{i}$ varied from $\sim 36$ vol. $\%$ at $H=0.66 \mathrm{~m}$ to $\sim 9 \mathrm{vol} . \%$ at $H=2.66 \mathrm{~m}$. The video records suggest that the granular mixtures were homogeneous just before impact, except at early and late stages of collapse where dense assemblages of particles with diameter of about 5-10 cm were present (Figure 3a-c).

\section{Scaling analysis}

We present a scaling analysis in order to evaluate the degree of dynamic similarity between the natural phenomena and our laboratory experiments. Table 2 gives some relevant physical parameters that control the dynamics of pyroclastic fountains and the resulting flows. For the latter we consider only the scaling parameters for dense granular-fluid flow because it is the dominant flow regime in the experiments in terms of particle mass transported. In this regime, the particle transport mechanism is essentially the transfer of momentum through collisional and/or frictional contacts between the particles and through gas-particle interactions. Table 2 also presents dimensionless numbers obtained from these parameters and identified in earlier studies (Burgisser et al., 2005; Burgisser and Bergantz, 2002; Carazzo and Jellinek, 2012; Iverson and Denlinger, 2001; Kavanagh et al., 2018; Roche, 2012; Roche and Carazzo, 2019; Sweeney and Valentine, 2017). The values of these numbers as well as their significance 
in term of physical processes are also indicated in Table 2. In general, the ranges of values of the dimensionless numbers in nature encompass those in the laboratory experiments. This is due to the fact that natural mixtures contain particles whose grain size span over at least three orders of magnitude whereas the particles used in experiments are nearly monodisperse. Therefore, experiments cannot explore the entire range of parameters exhibited by natural eruptions.

The Reynolds (Re), Richardson (Ri), Stokes (St) and Stability $(\Sigma)$ numbers can be used to characterize the dynamics of the dilute gas-particle mixtures in the fountain at the moment of impact (Table 2). Notice that, as common in laboratory studies, the Reynolds number in experiments is significantly smaller $\left(\operatorname{Re} \sim 10^{5}-10^{8}\right)$ than in nature $\left(\operatorname{Re} \sim 10^{9}-10^{13}\right)$ but high enough to ensure turbulent conditions (Andrews and Manga, 2012). The Richardson number in our experiments $\left(\mathrm{Ri} \sim 10^{0}-10^{5}\right)$ is similar or larger than that of pyroclastic fountains $(\mathrm{Ri} \sim$ $\left.10^{-3}-10^{3}\right)$. Large values of $\mathrm{Ri}$, in particular, indicate that the motion of our experimental suspensions is initially strongly dominated by gravity over inertial forces. The Stokes and Stability numbers both vary strongly in natural pyroclastic fountains due to the large range of particles sizes (i.e., $\mathrm{d} \sim 10^{-5}-10^{-2} \mathrm{~m}$ ). In our experiments, these numbers indicate poor to strong coupling between the fluid and the solid glass beads (St $\sim 10^{-3}-10^{1}, \Sigma \sim 10^{-4}-10^{-1}$ ). We note that these ranges of values are relatively close to those estimated in natural flows for coarse ash-sized particles ranging from $100 \mu \mathrm{m}$ to $1 \mathrm{~mm}$ (i.e., St $\sim 10^{-5}-10^{3}, \Sigma \sim 10^{-5}-10^{2}$, Table 2) suggesting that our experiments are suitable for studying the behaviour of these intermediate-sized particles. Overall, the values of Re, Ri, St, and $\Sigma$ indicate that our experimental falling mixtures are reasonable analogues of pyroclastic fountaining although they do not allow to explore the full range of physical regimes.

The dense granular flow resulting from fountain collapse can be characterized by an additional set of dimensionless numbers: the Darcy (Da) and Bagnold (Ba) numbers that apply to the proximal part of the flow, and the Savage ( $\mathrm{Sa}$ ) number that is relevant to the more distal part of the flow (Table 2). The values of the Darcy number in our experiments indicate that solid-fluid interactions dominate over collisional solid stresses (i.e., Da $>1$ ) and thus suggest that pore fluid pressure is likely to buffer particle interactions in proximal areas. The Bagnold number spans a relatively large range of values in our experiments $\left(\mathrm{Ba} \sim 10^{-3}-10^{2}\right)$ suggesting that either viscous fluid or collisional solid stresses dominate depending on the particle concentration, which correspond to macro-viscous to intermediate regimes (Iverson, 1997). Low Ba and high Da conditions in our experiments suggest that pore fluid pressure may be high in the impact zone. At late stage of flow emplacement, pore fluid pressure has diffused and becomes negligible, and the flow propagates in a dry granular regime described by the Savage number, where particle friction dominates over collisions (i.e., $\mathrm{Sa}<10^{-1}$ ). The respective values of the Darcy, Bagnold and Savage numbers indicate that our experimental granular flows are suitable physical analogues of dense pyroclastic flows (Table 2).

\section{Results}

\subsection{Granular mixture dynamics at the impact zone}

Figure 3 shows the different stages observed during an experiment. Immediately after opening the gate of the hopper, the collapsing granular mixture accelerated and dilated (Figure 3a-c) until it impacted the channel base (Figure 3d-e; Video S1). The mixture then deflated upon impingement and propagated laterally to form a dense granular flow overridden by a dilute suspension in the channel (Figure 3f-g; Video S2). The results presented in Figure 4, obtained from video analysis, show that the velocity of the mixture at the impact zone was very close to the free fall velocity 


$$
U_{i}=\sqrt{2 g H},
$$

with $g=9.81 \mathrm{~m} \mathrm{~s}^{-2}$ the gravitational acceleration. Notice that the range of values of $U_{i}$ observed (i.e., $\sim 3-7 \mathrm{~m} \mathrm{~s}^{-1}$ ) is one order of magnitude larger than the theoretical terminal settling velocity of individual particles estimated to be $\sim 0.4 \mathrm{~m} \mathrm{~s}^{-1}$ (Weit et al., 2018), suggesting that drag exerted by the ambient air on the mixture was much less than the one of a single particle. The thickness of the granular material at the impact zone increased first for a duration of $\sim 0.3-0.5$ $\mathrm{s}$ and then it decreased notably until $\sim 1.0-1.5 \mathrm{~s}$ after impact except for the smallest release height of $0.45 \mathrm{~m}$ (see supplementary material - Figure S1). Accumulation of the particles generated pore pressure signals such as shown in Figure 5. All experiments were characterized by an overpressure phase with a maximum magnitude $P_{\max } \sim 150-1500 \mathrm{~Pa}$. In most experiments, this phase of overpressure was followed by a secondary peak of lower magnitude of $\sim 100-1000 \mathrm{~Pa}$. The main first phase of overpressure was also preceded by an underpressure phase with minimum values of -30 to $-100 \mathrm{~Pa}$ in experiments where the particles initially impacted the channel between the back-wall and the pressure sensor (cf. Figure S2). This underpressure was likely generated by the slip of the granular material along the channel walls, as shown by earlier studies (Breard et al., 2019; Roche, 2012; Roche et al., 2010) but we acknowledge that we did not quantify the local velocity of the granular mixture at the impact zone. Synchronization of the pore pressure measurements with the high-speed videos permitted us to correlate the pressure signals to the stages of particle accumulation (Figure 5). The main peak of overpressure was clearly related to the maximum height of the bed of particles accumulated at the impact zone, whereas the second peak of overpressure, if present, occurred during the decrease of the bed thickness. Figure 6 shows the variation of the maximum or the average pore fluid pressure (recorded in the first second after impact) with the fall height. The maximum value of the pore fluid pressure showed no systematic variation with the drop height, however the average pressure did increase significantly with fall height.

In order to determine the amount of the weight of the particles counterbalanced by the pore fluid pressure at the impact zone, we estimated the lithostatic pressure such as

$$
P_{L}=C \rho_{p} g h_{b},
$$

with $C$ the particle concentration in the dense bed and $h_{b}$ the bed height above the pressure sensor, which is very close to the mean bed height (cf. Figure S3). Since the particle concentration at impact was unknown, we estimated it as follows. Video images at the time of the maximum bed height (cf. Figure S4) revealed the presence of air bubbles typical of dense but slightly expanded fluidized granular beds in about two thirds of the experiments and in all cases at $H \geq 2.45 \mathrm{~m}$. The presence of these bubbles suggested a maximum expansion of about $20 \%$ compared to the fully compacted state (as typical of the fine particles we used, cf. Geldart, 2004). Higher expansion would have prevented the formation of bubbles and rather favoured pervasive air escape (Rhodes, 2008). Therefore, considering the maximum concentration of the granular mixtures $C_{\max } \sim 58$ vol. \% at random packing, we assumed a particle concentration C $=0.8 \times C_{\max } \sim 46$ vol. $\%$ to estimate the evolution of the ratios $P / P_{L}$ of the pore fluid pressure over the lithostatic pressure with time. This ratio was only estimated for experiments with no initial underpressure phase, which occurred in one fourth of the experiments and never at $H=$ $0.95 \mathrm{~m}$. Figure 7 presents $P / P_{L}$ as function of time for three experiments (an additional analysis of an experiment at $H=2.95 \mathrm{~m}$ is shown in Figure S5). Maximum values of $P / P_{L}$ were measured at the moment both the thickness of accumulated material and the pore pressure were maximum. These values were between 0.1 and 0.55 , showing that the granular mixtures were partially fluidized during their compaction, with up to about half the weight of the particles being supported by the pore fluid pressure in some cases. However, the data reveal large variations owing to uncertainties in particle concentrations, which might have been lower than the assumed value of $\sim 46$ vol. $\%$. 


\subsection{Flow dynamics in the channel}

Flow emplacement occurred in three distinct phases as described by Rowley et al. (2014) (Figure 8). During phase 1, a fast-moving (up to $6 \mathrm{~m} \mathrm{~s}^{-1}$ ) thin $(<1 \mathrm{~cm}$ ) pulse of particles emerged immediately upon impact of the granular mixture and propagated laterally along the channel base (Figure 8a). During phase 2, a slower (up to $4.5 \mathrm{~m} \mathrm{~s}^{-1}$ ) and denser granular flow emplaced in pulsed waves and reached the maximum runout distance $L$. This dense flow was overridden by a dilute suspension of particles (Figure $8 \mathrm{~b}$ ). Phase 3 was characterized by a sustained aggradation of the deposit through a succession of thin flow pulses. During this phase, the dense granular flow commonly had surface waves propagating downstream at mean velocities of $\sim 1$ $3 \mathrm{~m} \mathrm{~s}^{-1}$ (close to the mean velocity of phase 2) and was fed by particles settling from the upper dilute suspension (Figure 8c). Only few particles were transported during phase 1 and most of the particles were carried in the flow pulses of phases 2 and 3. The maximum runout distance of the granular flow increased linearly with the fall height (Figure 9) according to

$$
L=0.63 H+1.15 \text {. }
$$

The kinematic data of the flows are presented in Figure 10. The dilute pulse during phase 1 propagated at nearly constant front velocity of $\sim 1.5-6 \mathrm{~m} \mathrm{~s}^{-1}$, which tended to increase with the fall height though not systematically (Figure 10a-b). In contrast, the front velocity of the dense flow during phase 2 varied, particularly at times when the afore-described surface waves reached the front. The mean front velocity of $\sim 1-4.5 \mathrm{~m} \mathrm{~s}^{-1}$ (determined from the mean slopes in Figure 10c) generally increased with the fall height (Figure 10d).

As the fall height increased, the morphology of the deposits was characterized by gentler surface slopes and thinner deposits at the impact zone and by more extended frontal areas (Figure 11a). The deposit aspect ratio $(\lambda)$, defined as the maximum height at the channel backwall over the deposit length, decreased from $\sim 0.15$ to $\sim 0.04$ at increasing fall heights (Figure 11b).

\section{Discussion}

Our experiments revealed that pore fluid pressure was generated at the impact zone of collapsing granular mixtures with various particle concentrations ranging from 9 to 36 vol. \%, which accumulated to form dense laterally-moving granular flows. Particle accumulation and formation of a dense flow were previously described by Rowley et al. (2014), Lube et al. (2015), Breard and Lube (2017) and Lube et al. (2019), for mixtures with initial solid volume concentrations as low as a few volume percent. Numerical simulations such as those of Sweeney and Valentine (2017), Valentine and Sweeney (2018) and Valentine (2020) suggest dense flows can emerge from collapsing granular mixtures with particle concentrations as low as $10^{-3}$ vol. $\%$. Note that there probably exists a regime for which the particle concentration is so low that the mixture remains dilute upon impact, which we could not explore in our experiments. Our study involving quasi monodisperse mixtures revealed a dilute suspension of particles that preceded and overrode the dense flow, as shown by Lube et al. (2015) and Breard and Lube (2017) for polydisperse pyroclastic materials. In our experiments, the suspension emerged rapidly upon impact and was ejected laterally without showing evidence of significant turbulent transport, so that particles settled fairly rapidly. This observation contrasts with the large-scale experiments of Lube et al. (2015), Breard and Lube (2017) and Lube et al. (2019), which generated faster and fully turbulent polydisperse suspensions.

Granular mixture deflation may be discussed in light of the recent numerical simulations of Sweeney and Valentine (2017), Valentine and Sweeney (2018) and Valentine (2020), who pointed out the fundamental effect of the particle Stokes number. These authors showed that particles well coupled to their carrier gas phase (at low St) follow the fluid streamlines so that 
the emerging lateral flow has particle concentration and speed similar to that of the collapsing mixture. In contrast, poorly-coupled particles (at high St) gather at the impact zone and form highly-concentrated granular flows overridden by a high-speed jet of expelled gas and fine particles. Our experiments show that particles at $\mathrm{St} \sim 10^{-3}-10^{1}$ can decouple from the fluid flow, so that the collapsing mixtures are prone to form dense flows upon impact, as discussed by Sweeney and Valentine (2017), Valentine and Sweeney (2018) and Valentine (2020). Inferring the behaviour of polydisperse volcanic mixtures in nature is not straightforward because (i) the particles have Stokes numbers spanning over a wide range of values, (ii) larger particles are better coupled to the gas in the presence of smaller, well-coupled particles, and (iii) shocks may develop in supersonic flows (Valentine and Sweeney, 2018). Assuming that volcanic mixtures contain a critical amount of relatively large and/or dense particles with sufficiently high Stokes numbers $(\mathrm{St} \geq 1)$ then dense flows may emerge from the impact zone of collapsing fountains. This is supported by the experiments of Lube et al. (2015) and Breard and Lube (2017) involving pyroclastic mixtures. We acknowledge, however, that this issue deserves further investigation.

The generation of gas pore pressure in the granular mixtures at the impact zone is a key feature of our study. Though we could not estimate accurately the lithostatic pressure in the granular beds, the values of pressure ratios suggest that a significant part of the weight of the particles (up to $\sim 50 \%$ ) was counterbalanced by pore pressure. This shows that the relative airparticle velocity upon impact generated drag sufficient to partially fluidize the dense granular mixtures. The granular material might have been fully fluidized locally as suggested by the bubbling commonly observed in the experiments. Considering that the superficial air velocity was

$$
U_{s}=\left(1-\varepsilon_{p}\right) U_{f} \quad,
$$

with $\varepsilon_{p}$ the particle volume fraction and $U_{f}$ the interstitial air velocity assumed to be close to the settling velocity of the mixtures, then $U_{s}$ was of the order of $1 \mathrm{~m} \mathrm{~s}^{-1}$, that is, two orders of magnitude larger than the minimum fluidization velocity of the particles of the order of $10 \mathrm{~mm}$ $\mathrm{s}^{-1}$. Our results are in agreement with those of Chédeville and Roche (2018) who considered an experimental configuration similar to ours (but without any lateral flow) and measured pore pressure generated by deflation of various types of granular materials. It is worth noting that in nature the amount of particle weight counterbalanced by pore pressure is likely to be higher than in our experiments since (i) the impact velocity is much larger than in the analogue smallscale configuration while the permeability of the (concentrated) pyroclastic mixtures is commonly smaller than that of the granular material we used and (ii) heating and expansion of the ingested ambient cold air may cause thermal pressurization as shown by Chédeville and Roche 2018. Further experiments should validate this hypothesis.

In our experiments, the pore fluid pressure in the dense flows emerging from the impact zone diffused slowly and favoured propagation of the granular mixture, which eventually formed thin, elongated deposits. In this regard, notice that the lowest deposit aspect ratios of 0.04 at the largest fall heights were close to those of $\sim 0.02-0.03$ reported for deposits of dambreak granular flows generated from release of initially fluidized granular columns (e.g. see review of Delanney at al. 2017). Lube et al. (2019) inferred that the pore fluid pressure they measured in their experimental flows was due to internal flow dynamics. Our results show that pore pressure can be generated at the impact zone and then advected as the flow propagates. The relative contributions of pore pressure generated upon impact or through flow dynamics remains an open question that requires further investigation. In nature, we expect the generation of high gas pore pressure and the fluidization of the pyroclastic material to occur at the impact zone of pyroclastic fountains since volcanic mixtures have mean grain sizes similar to that in our experiments and as collapse velocities are much larger than in experiments. 
Another notable outcome of our experiments is the linear dependence of the flow runout distance with the drop height as shown by equation (5). Flow runout results essentially from conversion of potential energy to kinetic energy as well as gravitational spreading of the granular mass. The contribution of the latter can be estimated from equation (5) with $H=0$, so that $L=1.15 \mathrm{~m}$. In natural systems, we expect the constant in equation 5 (i.e. $1.15 \mathrm{~m}$ ) to increase with the total mass of material involved in the pyroclastic fountains. The initial particle concentration, which varies with the mode of release, has a secondary influence, if any. Considering conversion of energies given by $m V_{f}^{2} / 2=m g H$, with $m$ the granular mass, $V_{f}=$ $L / t_{f}$ the flow velocity, and $t_{f}$ the time of flow emplacement that scales with the characteristic particle fall time $(H / g)^{\frac{1}{2}}$, gives $L \sim H$. This is in line with the findings of experiments on dambreak flows generated from release of static, packed granular columns (see review of Delannay et al., 2017 and related discussion). First, the runout distance of unidirectional flows in a channel scales with the column height, provided boundary effects are weak (notice that the runout of axisymmetric flows scales with $H^{\frac{1}{2}}$ due to lateral spreading). Second, the runout data for columns dropped from a given height off the base obey to the scaling laws defined for dambreak flows (Lube et al., 2004). Assuming that similar scaling laws may apply to natural cases, we conclude that the runout of dense pyroclastic flows will have a linear or a square root dependence with the fountain height depending on whether the flows will propagate in a preferential direction (i.e., partial column collapse channelized by topography) or radially (i.e., total collapse), respectively. Furthermore, the prefactors in the scaling laws (i.e. 0.63 in equation 5) are expected to increase with the length scale of the system because the flow runout will also increase with the duration of pore pressure diffusion, which increases with the flow depth for a given material permeability. However, more numerical or laboratory studies are required to provide an accurate prediction of the dependence of the flow runout distance on the flow thickness. The experimental scaling laws presented here are thereby only to be used to understand qualitatively the relation between the flow runout distance and the fountain height.

\section{Conclusions}

We carried out analogue experiments on pyroclastic fountain collapse in order to investigate the mechanisms at the deflation zone and in the resulting flows. Mixtures of particles with Stokes number $\sim 10^{-3}-10^{1}$, equivalent to particles of diameter $\sim 0.1-1 \mathrm{~mm}$ in nature, where released from a hopper positioned at different heights above a channel. The particle concentration of the collapsing mixture at impact varied within the range 9-36 vol. \%, increasing inversely with the drop height. The main conclusions of this study are the following. 1. The particles decoupled from the interstitial gas at the impingement surface, regardless of the mean particle concentration just before impact. The mixtures deflated and were directed laterally to form dense granular flows.

2. High differential air-particle velocity and drag forces during deflation generated pore fluid pressure, which caused partial fluidization of the dense granular mixture.

3. The runout distance of the dense flows scaled with the drop height, which is consistent with published results on dam-break unidirectional granular flows. This suggests that flow runout results fundamentally from a simple conversion of potential to kinetic energy and that, for the conditions tested here, initial particle concentration is a second order parameter.

4. Pyroclastic fountains containing large amounts of particles with Stokes numbers of the order $10^{-3}-10^{-1}$ similar to those in our experiments are expected to generate dense pyroclastic flows with pore fluid pressure. The flow runout may have a linear or a square root dependence with the fountain height depending on whether propagation is unidirectional or radial, respectively. 


\section{Acknowledgements}

This research was financed by the French National Research Agency RAVEX project (ANR16-CE03-0002) and by the French National Research Institute for Sustainable Development (IRD). This is Laboratory of Excellence ClerVolc contribution XXX. We thank Ben Andrews and Gert Lube for insightful reviews.

\section{References}

Andrews, B.J., Manga, M., 2012. Experimental study of turbulence, sedimentation, and coignimbrite mass partitioning in dilute pyroclastic density currents. Journal of Volcanology and Geothermal Research 225-226, 30-44. https://doi.org/10.1016/j.jvolgeores.2012.02.011

Baxter, P.J., Boyle, R., Cole, P., Neri, A., Spence, R., Zuccaro, G., 2005. The impacts of pyroclastic surges on buildings at the eruption of the Soufrière Hills volcano, Montserrat. Bull Volcanol 67, 292313. https://doi.org/10.1007/s00445-004-0365-7

Baxter, P.J., Jenkins, S., Seswandhana, R., Komorowski, J.-C., Dunn, K., Purser, D., Voight, B., Shelley, I., 2017. Human survival in volcanic eruptions: Thermal injuries in pyroclastic surges, their causes, prognosis and emergency management. Burns. https://doi.org/10.1016/j.burns.2017.01.025

Breard, E.C.P., Dufek, J., Lube, G., 2018. Enhanced Mobility in Concentrated Pyroclastic Density Currents: An Examination of a Self-Fluidization Mechanism. Geophys. Res. Lett. 45, 654-664. https://doi.org/10.1002/2017GL075759

Breard, E.C.P., Dufek, J., Roche, O., 2019. Continuum Modeling of Pressure-Balanced and Fluidized Granular Flows in 2-D: Comparison With Glass Bead Experiments and Implications for Concentrated Pyroclastic Density Currents. J. Geophys. Res. Solid Earth 124, 5557-5583. https://doi.org/10.1029/2018JB016874

Breard, E.C.P., Lube, G., 2017. Inside pyroclastic density currents - uncovering the enigmatic flow structure and transport behaviour in large-scale experiments. Earth and Planetary Science Letters 458, 22-36. https://doi.org/10.1016/j.epsl.2016.10.016

Burgisser, A., Bergantz, G.W., 2002. Reconciling pyroclastic flow and surge: the multiphase physics of pyroclastic density currents. Earth and Planetary Science Letters 202, 405-418. https://doi.org/10.1016/S0012-821X(02)00789-6

Burgisser, A., Bergantz, G.W., Breidenthal, R.E., 2005. Addressing complexity in laboratory experiments: the scaling of dilute multiphase flows in magmatic systems. Journal of Volcanology and Geothermal Research 141, 245-265. https://doi.org/10.1016/j.jvolgeores.2004.11.001

Carazzo, G., Jellinek, A.M., 2012. A new view of the dynamics, stability and longevity of volcanic clouds. Earth and Planetary Science Letters 325-326, 39-51. https://doi.org/10.1016/j.eps1.2012.01.025

Cas, R.A.F., Wright, H.M.N., Folkes, C.B., Lesti, C., Porreca, M., Giordano, G., Viramonte, J.G., 2011. The flow dynamics of an extremely large volume pyroclastic flow, the 2.08-Ma Cerro Galán Ignimbrite, NW Argentina, and comparison with other flow types. Bulletin of Volcanology 73, 15831609. https://doi.org/10.1007/s00445-011-0564-y

Chédeville, C., Roche, O., 2018. Autofluidization of collapsing bed of fine particles: Implications for the emplacement of pyroclastic flows. Journal of Volcanology and Geothermal Research 368, 91-99. https://doi.org/10.1016/j.jvolgeores.2018.11.007

Delannay, R., Valance, A., Mangeney, A., Roche, O., Richard, P., 2017. Granular and particle-laden 
flows: from laboratory experiments to field observations. J. Phys. D: Appl. Phys. 50, 053001. https://doi.org/10.1088/1361-6463/50/5/053001

Dellino, P., Dioguardi, F., Zimanowski, B., Büttner, R., Mele, D., La Volpe, L., Sulpizio, R., Doronzo, D.M., Sonder, I., Bonasia, R., Calvari, S., Marotta, E., 2010. Conduit flow experiments help constraining the regime of explosive eruptions. Journal of Geophysical Research 115. https://doi.org/10.1029/2009JB006781

Dellino, P., Zimanowski, B., Büttner, R., La Volpe, L., Mele, D., Sulpizio, R., 2007. Large-scale experiments on the mechanics of pyroclastic flows: Design, engineering, and first results: experiments on pyroclastic flows. Journal of Geophysical Research: Solid Earth 112.

https://doi.org/10.1029/2006JB004313

Doocy, S., Daniels, A., Dooling, S., Gorokhovich, Y., 2013. The Human Impact of Volcanoes: a Historical Review of Events 1900-2009 and Systematic Literature Review. PLoS Curr 5. https://doi.org/10.1371/currents.dis.841859091a706efebf8a30f4ed7a1901

Druitt, T.H., Sparks, R.S.J., 1982. A proximal ignimbrite breccia facies on santorini , Greece. Journal of Volcanology and Geothermal Research 13, 147-171. https://doi.org/10.1016/0377-0273(82)900257

Geldart, D., 2004. Expansion of Gas Fluidized Beds. Ind. Eng. Chem. Res. 43, 5802-5809. https://doi.org/10.1021/ie040180b

Guzmán, S., Doronzo, D.M., Martí, J., Seggiaro, R., 2020. Characteristics and emplacement mechanisms of the Coranzulí ignimbrites (Central Andes). Sedimentary Geology 405, 105699. https://doi.org/10.1016/j.sedgeo.2020.105699

Iverson, R.M., 1997. The physics of debris flows. Reviews of Geophysics 35, 245-296. https://doi.org/10.1029/97RG00426.

Iverson, R.M., Denlinger, R.P., 2001. Flow of variably fluidized granular masses across threedimensional terrain. Journal of Geophysical Research 106, 537-552. https://doi.org/10.1029/2000JB900329.

Kavanagh, J.L., Engwell, S.L., Martin, S.A., 2018. A review of laboratory and numerical modelling in volcanology. Solid Earth 9, 531-571. https://doi.org/10.5194/se-9-531-2018

Lube, G., Breard, E.C.P., Cronin, S.J., Jones, J., 2015. Synthesizing large-scale pyroclastic flows: Experimental design, scaling, and first results from PELE: Large-scale PDC experiments. Journal of Geophysical Research: Solid Earth 120, 1487-1502. https://doi.org/10.1002/2014JB011666

Lube, G., Breard, E.C.P., Jones, J., Fullard, L., Dufek, J., Cronin, S.J., Wang, T., 2019. Generation of air lubrication within pyroclastic density currents. Nat. Geosci. 12, 381-386.

https://doi.org/10.1038/s41561-019-0338-2

Lube, G., Huppert, H.E., Sparks, R.S.J., Hallworth, M.A., 2004. Axisymmetric collapses of granular columns. Journal of Fluid Mechanics 508, 175-199. https://doi.org/10.1017/S0022112004009036

Michaud-Dubuy, A., Carazzo, G., Kaminski, E., Girault, F., 2018. A revisit of the role of gas entrapment on the stability conditions of explosive volcanic columns. Journal of Volcanology and Geothermal Research 357, 349-361. https://doi.org/10.1016/j.jvolgeores.2018.05.005

Pacheco-Hoyos, J.G., Aguirre-Díaz, G.J., Dávila-Harris, P., 2018. Boiling-over dense pyroclastic density currents during the formation of the $\sim 100 \mathrm{~km} 3$ Huichapan ignimbrite in Central Mexico: Stratigraphic and lithofacies analysis. Journal of Volcanology and Geothermal Research 349, 268282. https://doi.org/10.1016/j.jvolgeores.2017.11.007

Rhodes, M., 2008. Introduction to Particle Technology. John Wiley \& Sons, Ltd, Chichester, UK. https://doi.org/10.1002/9780470727102 
Roche, O., 2012. Depositional processes and gas pore pressure in pyroclastic flows: an experimental perspective. Bulletin of Volcanology 74, 1807-1820. https://doi.org/10.1007/s00445-012-0639-4

Roche, O., Buesch, D.C., Valentine, G.A., 2016. Slow-moving and far-travelled dense pyroclastic flows during the Peach Spring super-eruption. Nature Communications 7, 10890.

https://doi.org/10.1038/ncomms 10890

Roche, O., Carazzo, G., 2019. The contribution of experimental volcanology to the study of the physics of eruptive processes, and related scaling issues: A review. Journal of Volcanology and Geothermal Research 384, 103-150. https://doi.org/10.1016/j.jvolgeores.2019.07.011

Roche, O., Montserrat, S., Niño, Y., Tamburrino, A., 2010. Pore fluid pressure and internal kinematics of gravitational laboratory air-particle flows: Insights into the emplacement dynamics of pyroclastic flows. Journal of Geophysical Research 115. https://doi.org/10.1029/2009JB007133

Rowley, P.J., Roche, O., Druitt, T.H., Cas, R., 2014. Experimental study of dense pyroclastic density currents using sustained, gas-fluidized granular flows. Bulletin of Volcanology 76. https://doi.org/10.1007/s00445-014-0855-1

Schneider, C.A., Rasband, W.S., Eliceiri, K.W., 2012. NIH Image to ImageJ: 25 years of image analysis. Nat. Methods 9, 671-675. https://doi.org/10.1038/nmeth.2089

Sparks, R.S.J., Wilson, L., 1976. A model for the formation of ignimbrite by gravitationalcolumn collapse. JL geol. Soc. Lond. 132, 441-451.

Sweeney, M.R., Valentine, G.A., 2017. Impact zone dynamics of dilute mono- and polydisperse jets and their implications for the initial conditions of pyroclastic density currents. Physics of Fluids 29, 093304. https://doi.org/10.1063/1.5004197

Valentine, G.A., 2020. Initiation of dilute and concentrated pyroclastic currents from collapsing mixtures and origin of their proximal deposits. Bull Volcanol 82, 20. https://doi.org/10.1007/s00445020-1366-x

Valentine, G.A., Sweeney, M.R., 2018. Compressible Flow Phenomena at Inception of Lateral Density Currents Fed by Collapsing Gas-Particle Mixtures. J. Geophys. Res. Solid Earth 123, 12861302. https://doi.org/10.1002/2017JB015129

Valentine, G.A., Wohletz, K.H., 1989. Numerical models of Plinian eruption columns and pyroclastic flows. J. Geophys. Res. 94, 1867. https://doi.org/10.1029/JB094iB02p01867

Weit, A., Roche, O., Dubois, T., Manga, M., 2018. Experimental Measurement of the Solid Particle Concentration in Geophysical Turbulent Gas-Particle Mixtures. J. Geophys. Res. Solid Earth 123, 3747-3761. https://doi.org/10.1029/2018JB015530

Woods, A.W., 1988. The fluid dynamics and thermodynamics of eruption columns. Bulletin of Volcanology 50, 169-193. https://doi.org/10.1007/BF01079681 


\section{Table captions}

Table 1. Summary of experiments showing the varying parameters: fall height $(\mathrm{H})$, region of interest (ROI) and number of repeats of experiments. We filmed either the impact zone, for visualising the mechanisms occurring during compaction of the granular mixture, or the channel to study the subsequent flow. In experiment 13, we focused on the column to qualitatively document the dilation of the granular mixture during its fall. Particles were spherical glass beads with a mean diameter of $75 \pm 15 \mu \mathrm{m}$. The particle properties, initial mass flux and channel inclination (horizontal) were kept constant.

\begin{tabular}{|c|c|c|c|}
\hline Experiment number & Fall height $\mathbf{H}$ (m) & ROI & Number of repeats \\
\hline 1 & 0.45 & Impact & 4 \\
\hline 2 & 0.45 & Channel & 2 \\
\hline 3 & 0.95 & Impact & 6 \\
\hline 4 & 0.95 & Channel & 3 \\
\hline 5 & 1.45 & Impact & 5 \\
\hline 6 & 1.45 & Channel & 2 \\
\hline 7 & 1.95 & Impact & 5 \\
\hline 8 & 1.95 & Channel & 1 \\
\hline 9 & 2.45 & Impact & 5 \\
\hline 10 & 2.45 & Channel & 1 \\
\hline 11 & 2.95 & Impact & 4 \\
\hline 12 & 2.95 & Channel & 2 \\
\hline 13 & 2.95 & Column & 1 \\
\hline
\end{tabular}


Table 2. Typical variables and dimensionless numbers associated with pyroclastic fountains compared with experimental values. Variables and definitions of dimensionless numbers are from ${ }^{(a)}$ Burgisser et al. (2005); ${ }^{(b)}$ Carazzo and Jellinek (2012); ${ }^{(c)}$ Roche (2012); ${ }^{(d)}$ Roche and Carazzo (2019) and ${ }^{(\mathrm{e})}$ Sweeney and Valentine (2017). We estimate the viscosity of the particlegas mixture from the Einstein-Roscoe formula $\mu_{m}=\mu\left(1-\varepsilon_{p} / \varepsilon_{p}^{\max }\right)^{-2.5}$, with $\mu=10^{-5} \mathrm{~Pa} \mathrm{~s}$ the dynamic viscosity of air and $\varepsilon_{p}^{\max }=0.64$ the maximum particle volume fraction of randomly packed particles.

\begin{tabular}{|c|c|c|c|c|}
\hline \multicolumn{5}{|c|}{ Material, dynamics and dimensions } \\
\hline Parameter name & & $\begin{array}{l}\text { Pyroclastic } \\
\text { fountains }\end{array}$ & Experiments & Units \\
\hline Particle diameter & $d$ & $10^{-5}-10^{-2(\mathrm{~d})}$ & $75 \times 10^{-6}$ & $\mathrm{~m}$ \\
\hline Gas dynamic viscosity & $\mu$ & $10^{-5(\mathrm{a})}$ & $10^{-5}$ & Pa s \\
\hline Ambient air density & $\rho_{a}$ & 1.2 & 1.2 & $\mathrm{~kg} \mathrm{~m}^{-3}$ \\
\hline Particle density & $\rho_{p}$ & $700-2500^{(\mathrm{c})}$ & 2500 & $\mathrm{~kg} \mathrm{~m}^{-3}$ \\
\hline $\begin{array}{l}\text { Particle volume fraction } \\
\text { (fountain and flow) }\end{array}$ & $\varepsilon_{p}$ & $10^{-4}-10^{-1(\mathrm{~b})}$ & $0.09-0.64$ & - \\
\hline $\begin{array}{l}\text { Particle-gas mixture } \\
\text { dynamic viscosity }\end{array}$ & $\mu_{m}$ & $10^{-5}-2 \times 10^{-5}$ & $10^{-5}-10^{-4}$ & Pas \\
\hline $\begin{array}{l}\text { Mixture density } \\
\text { (fountain and flow) }\end{array}$ & $\rho$ & $1-1000$ & $200-1600$ & $\mathrm{~kg} \mathrm{~m}^{-3}$ \\
\hline $\begin{array}{l}\text { Permeability } \\
\text { (fountain and flow) }\end{array}$ & $\kappa$ & $10^{-14}-10^{-9(\mathrm{c})}$ & $10^{-13}-10^{-8}$ & $\mathrm{~m}^{2}$ \\
\hline Particle settling velocity & $V_{s}$ & $10^{-3}-10^{4}$ & $10^{-2}-10^{0}$ & $\mathrm{~m} \mathrm{~s}^{-1}$ \\
\hline Mixture fall velocity & $U$ & $100-250^{(\mathrm{e})}$ & $3-8$ & $\mathrm{~m} \mathrm{~s}^{-1}$ \\
\hline Radius of impact zone & $R$ & $70-420$ & 0.1 & $\mathrm{~m}$ \\
\hline Collapse height & $H$ & $500-3000$ & $0.5-3$ & $\mathrm{~m}$ \\
\hline Flow velocity & $V_{f}$ & $10-150^{(\mathrm{d})}$ & $1-5$ & $\mathrm{~m} \mathrm{~s}^{-1}$ \\
\hline Flow thickness & $h$ & $1-50^{(\mathrm{c})}$ & $0.05-0.2$ & $\mathrm{~m}$ \\
\hline Flow shear rate & $\gamma$ & $0.2-150$ & $5-100$ & $\mathrm{~s}^{-1}$ \\
\hline
\end{tabular}

\section{Dimensionless numbers}

Name

Pyroclastic fountains

Reynolds

$(\mathrm{Re})$

$$
R e=\frac{R U \rho}{\mu_{m}}
$$

$10^{9}-10^{13}$

$10^{5}-10^{8}$

Richardson

(Ri)

$$
R i=\frac{H g^{\prime}}{U^{2}} \quad 10^{-3}-10^{3} \quad 10^{0}-10^{5}
$$

Stokes (St)

$$
S t=\frac{\left(\rho_{p}-\rho_{a}\right) d^{2} U}{18 \mu_{m} R}
$$

$10^{-5}-10^{3}$

$10^{-3}-10^{1}$
Inertial forces over viscous forces (fountain): turbulent flow

Potential energy over kinetic energy (fountain): potential energy dominates

Particle response time over timescale of the flow (fountain): efficient to poor gas-particle coupling 


\begin{tabular}{|c|c|c|c|c|}
\hline Stability $(\Sigma)$ & $\Sigma=\frac{\left(\rho_{p}-\rho_{a}\right) g d^{2}}{18 \mu_{m} U}$ & $10^{-5}-10^{2}$ & $10^{-4}-10^{-1}$ & $\begin{array}{l}\text { Particle settling velocity over } \\
\text { flow velocity (fountain): } \\
\text { efficient gas-particle coupling }\end{array}$ \\
\hline Savage (Sa) & $S a=\frac{\rho_{p} \gamma^{2} d^{2}}{\left(\rho_{p}-\rho_{a}\right) g h}$ & $10^{-15}-10^{-1}$ & $10^{-5}-10^{-2}$ & $\begin{array}{l}\text { Ratio of grain collisional to } \\
\text { frictional stresses (distal } \\
\text { lateral flow): frictional regime }\end{array}$ \\
\hline $\begin{array}{l}\text { Bagnold } \\
\text { (Ba) }\end{array}$ & $B a=\frac{\rho_{p} \gamma d^{2} \varepsilon_{p}}{\mu_{m}\left(1-\varepsilon_{p}\right)}$ & $10^{-7}-10^{5}$ & $10^{-3}-10^{2}$ & $\begin{array}{l}\text { Ratio of collisional solid over } \\
\text { viscous fluid stresses } \\
\text { (proximal lateral flow): } \\
\text { macro-viscous to transitional } \\
\text { regime }\end{array}$ \\
\hline Darcy (Da) & $D a=\frac{\mu_{m}}{\rho_{p} \gamma \kappa \varepsilon_{p}}$ & $10^{-1}-10^{11}$ & $10^{1}-10^{8}$ & $\begin{array}{l}\text { Viscous fluid-particle stresses } \\
\text { over particle inertial stresses } \\
\text { (proximal lateral flow): solid- } \\
\text { fluid interactions regime } \\
\text { (pore fluid pressure buffers } \\
\text { particle interactions) }\end{array}$ \\
\hline
\end{tabular}




\section{Figures}

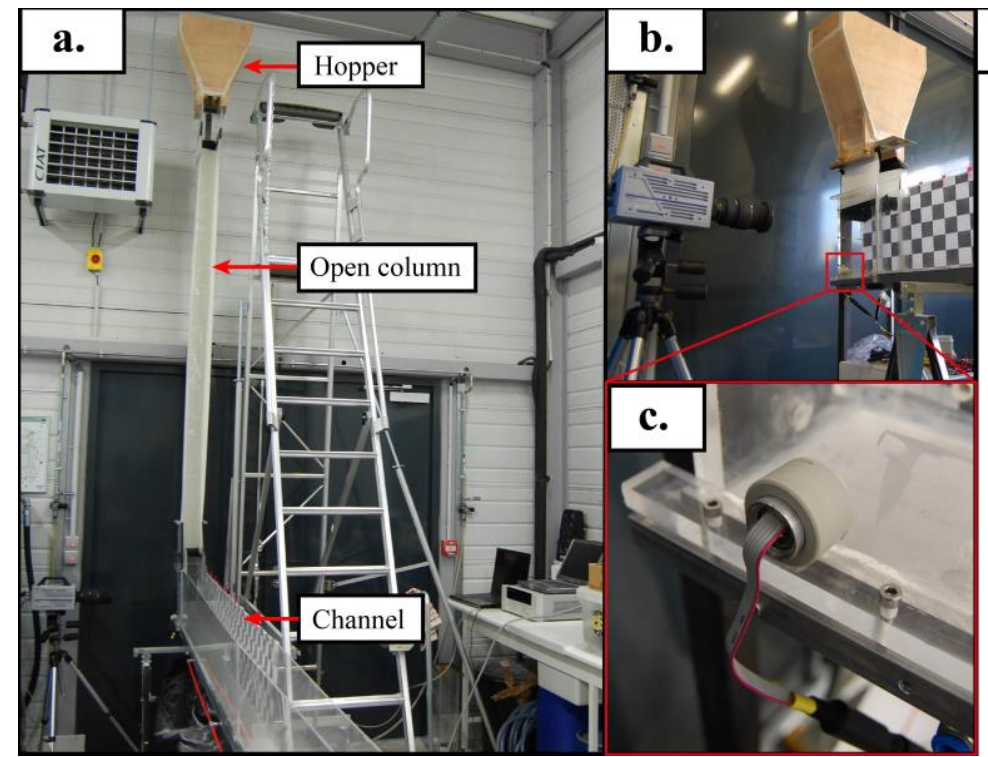

d.

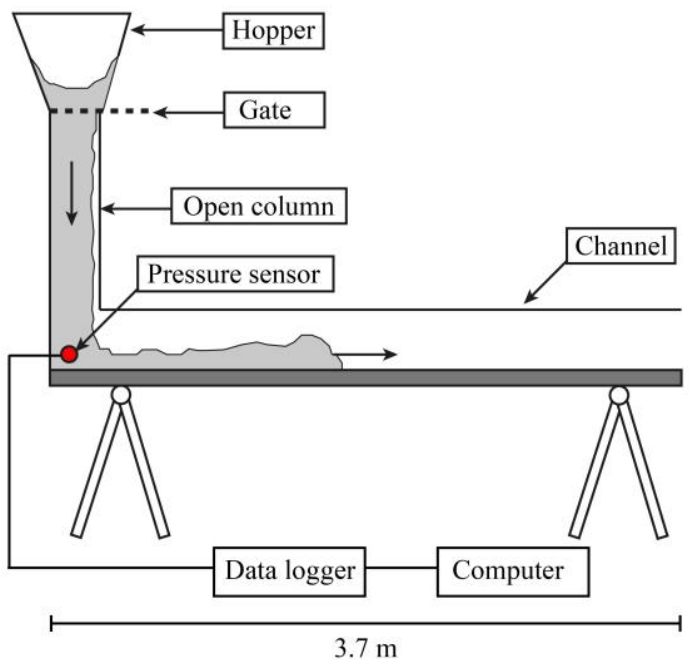

Figure 1. Experimental apparatus. (a) Longitudinal view with the hopper in the highest position. (b) Hopper in the lowest position and high-speed camera set to monitor the impact zone. (c) Pressure sensor at the sidewall of the impact zone. (d) Sketch of the experimental setup. 


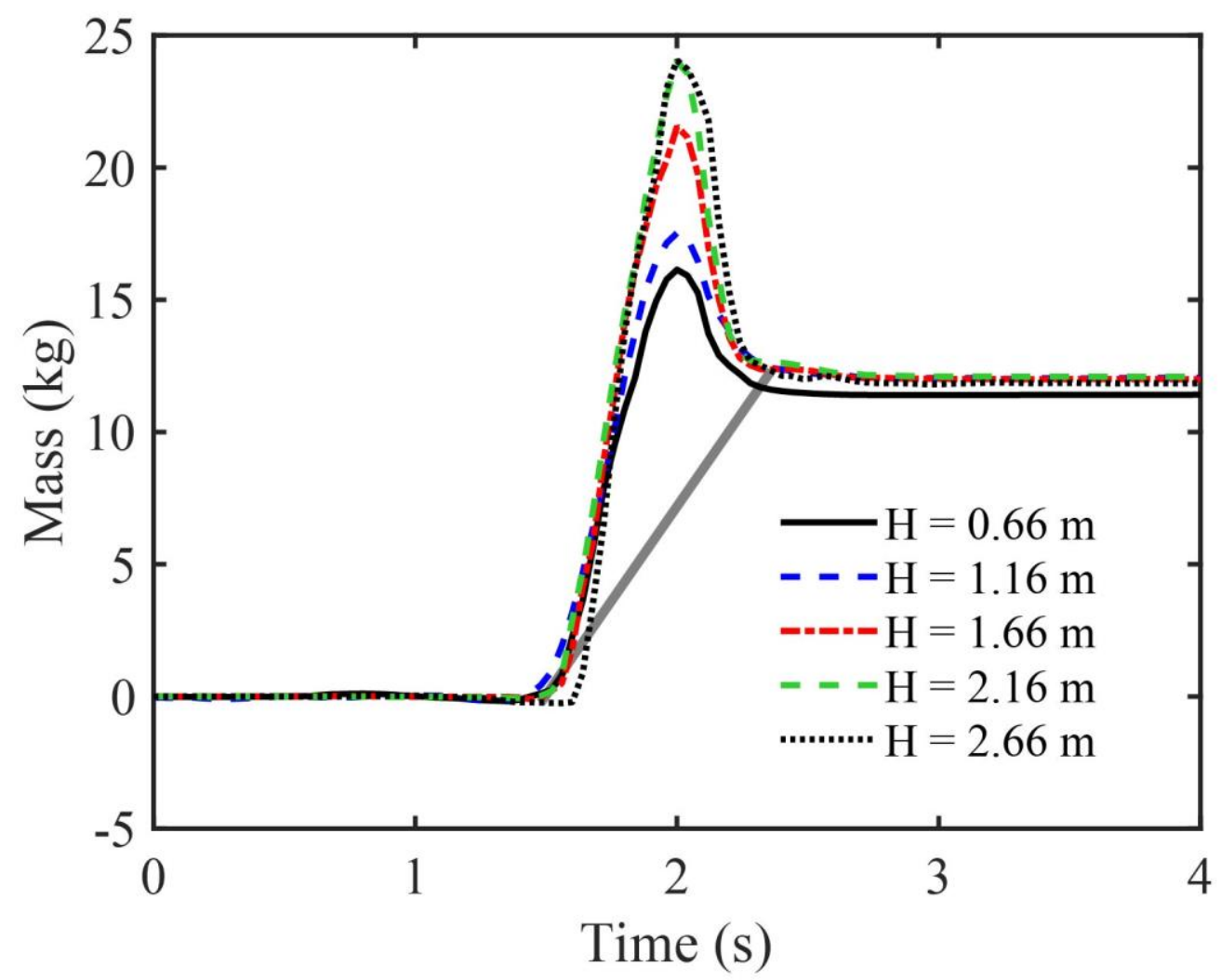

Figure 2. Particle supply from the hopper recorded by the static scale. The mass of particles released is shown as a function of time for five different fall heights, $H$. Notice that the apparent mass measured is larger than that released $(12 \mathrm{~kg}$, recovered after $\sim 2.3 \mathrm{~s})$ because of the nonzero velocity of the particles at impact in the container. Therefore, we estimated the timeaveraged mass flux from the slope of the solid grey line indicating the time at which the initial mass in the hopper was recovered. 


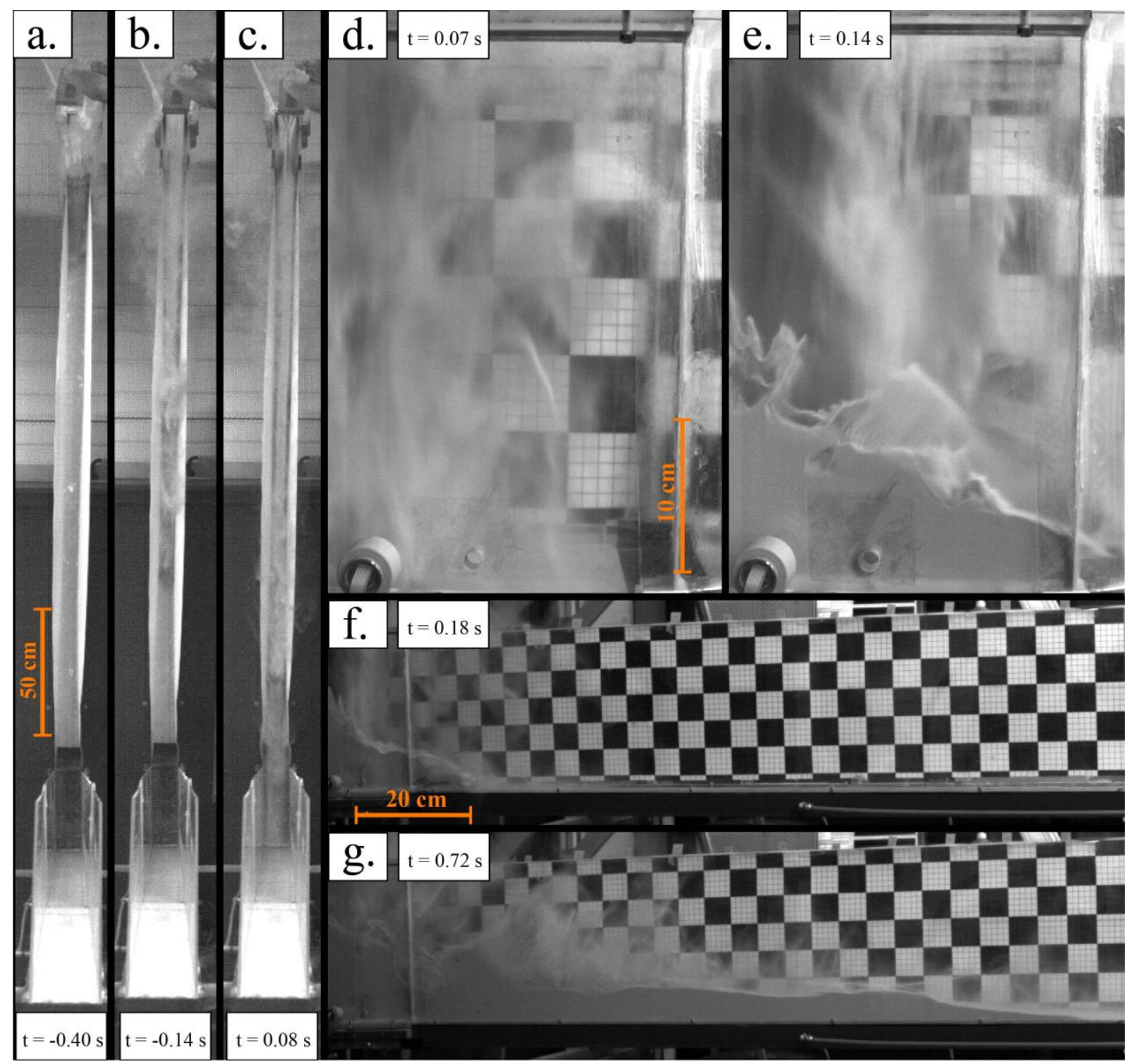

Figure 3. Stages observed in the experiments. a. b. c. Acceleration and dilation of the granular mixture inside the open column upon release from the hopper (experiment 13; Table 1). d. e. Impact of the granular mixture onto the channel base and accumulation of particles (experiment 9; Table 1). f. g. Lateral propagation of the granular flow (experiment 10; Table 1). The time $t$ $=0 \mathrm{~s}$ corresponds to the arrival of particles at the impact zone. 


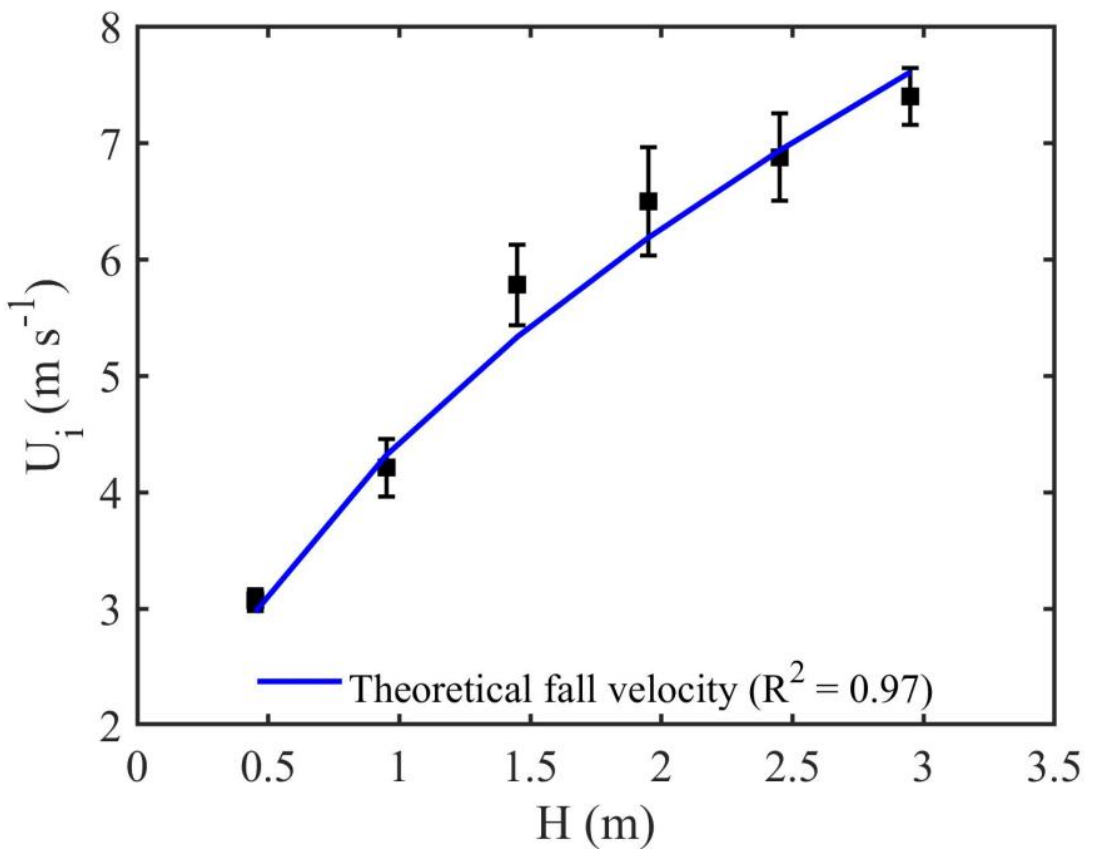

Figure 4. Fall velocity of the particles at the impact zone as a function of fall height $H$ (solid symbols). The blue curve represents the predicted free fall velocity using $U_{i}=\sqrt{2 g H}$. 

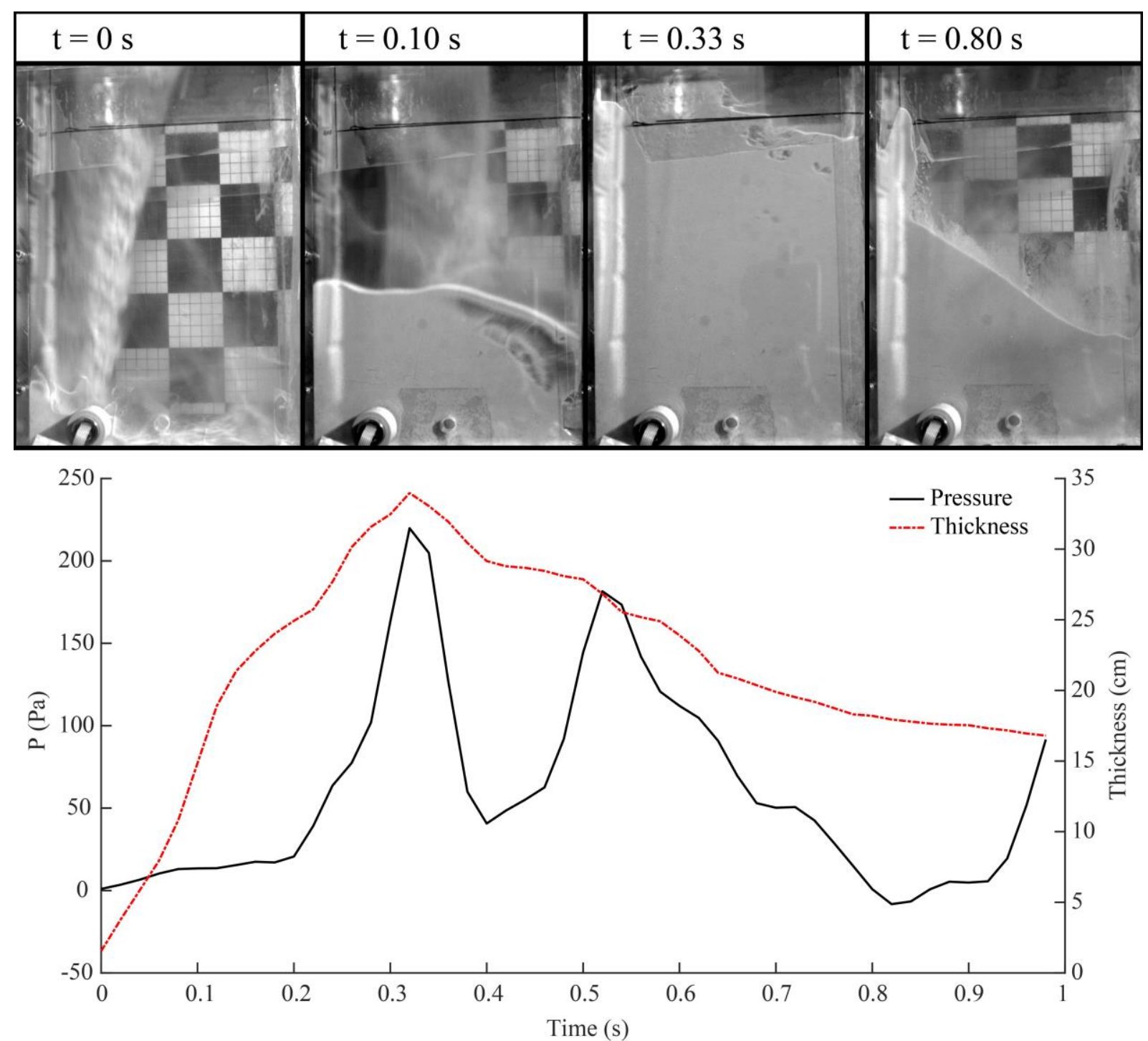

Figure 5. Pore fluid pressure ( $P$; solid black line) and thickness of the granular material (dashdotted red line) as a function of time for experiment $5(H=1.45 \mathrm{~m}$; Table 1$)$. Images of the impact zone are synchronized with the pressure signal and show the accumulation of the granular mixture. We could not investigate the motion of the granular mixture after impact in order to determine the contribution of the dynamic pressure on $P$. 

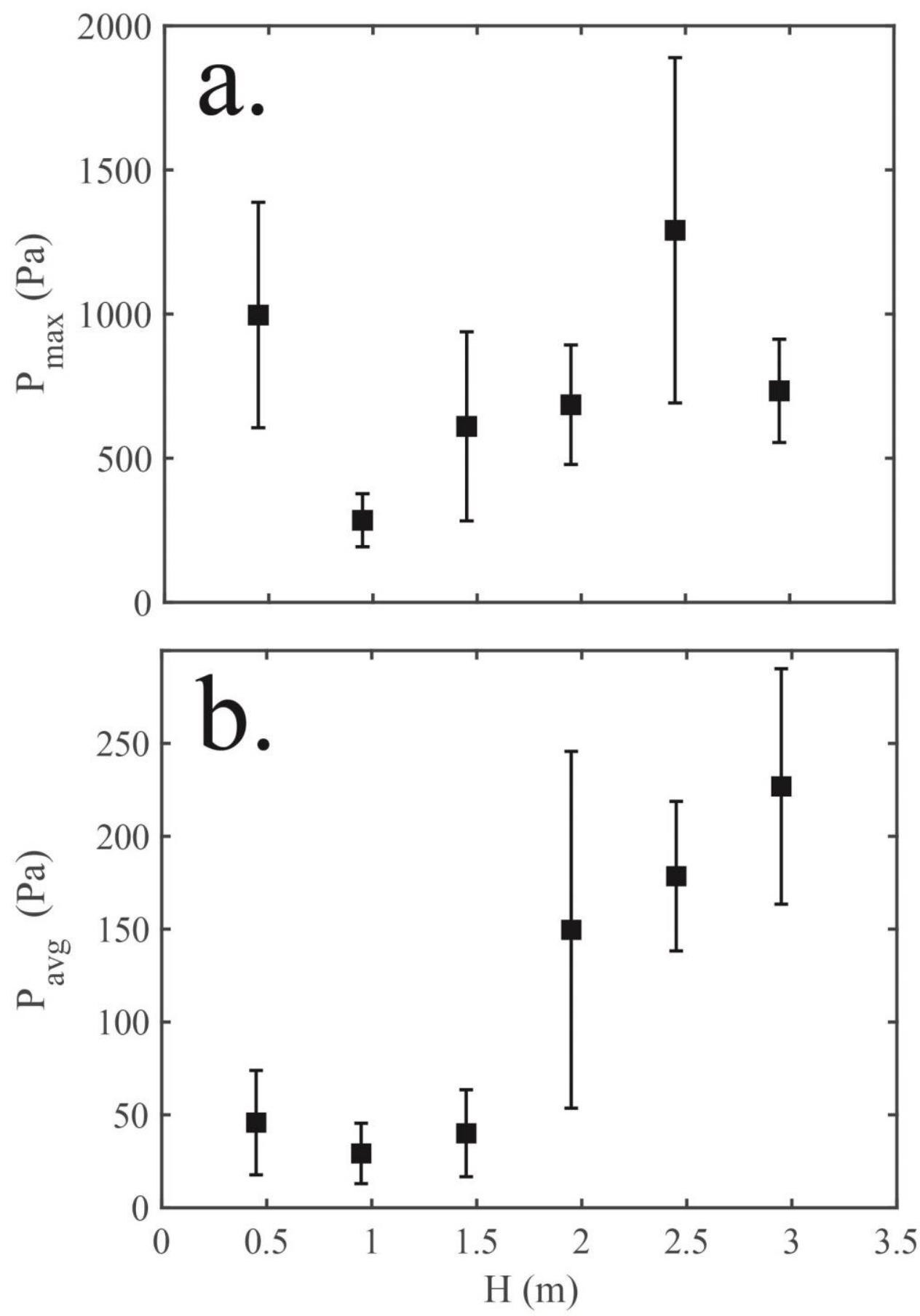

Figure 6. a. Maximum pore fluid pressure $P_{\max }$ measured at impact zone as a function of the fall height, $H$. b. Average pore fluid pressure $P_{\text {avg }}$ generated in the first second following impact, as a function of $H$. 

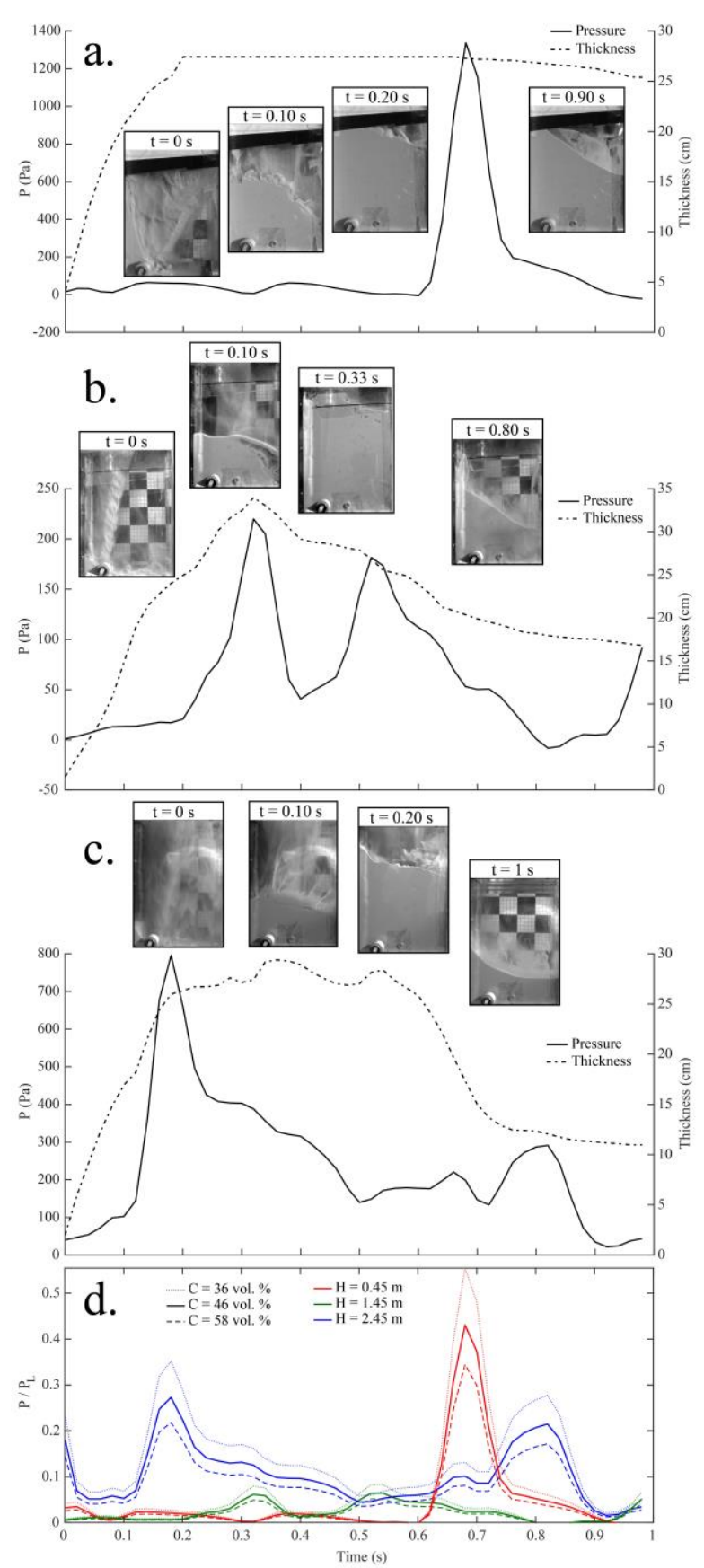

Figure 7. Pore fluid pressure and thickness of the granular bed measured at impact zone as function of time for a. experiment $1(H=0.45 \mathrm{~m}$; Table 1$)$, b. experiment $5(H=1.45 \mathrm{~m}$; Table 1), and c. experiment $9\left(H=2.45 \mathrm{~m}\right.$; Table 1). d. Ratio $P / P_{L}$ of the pore fluid pressure over the lithostatic pressure of the granular bed as a function of time for the experiments presented above, assuming different particle concentrations. The minimum bed concentration $C=36$ vol. $\%$ corresponds to the maximum concentration of the falling mixture, and the maximum concentration $C=58$ vol. $\%$ is that of a loosely packed bed. Higher resolution images of the impact zone are provided in Figure S6. 


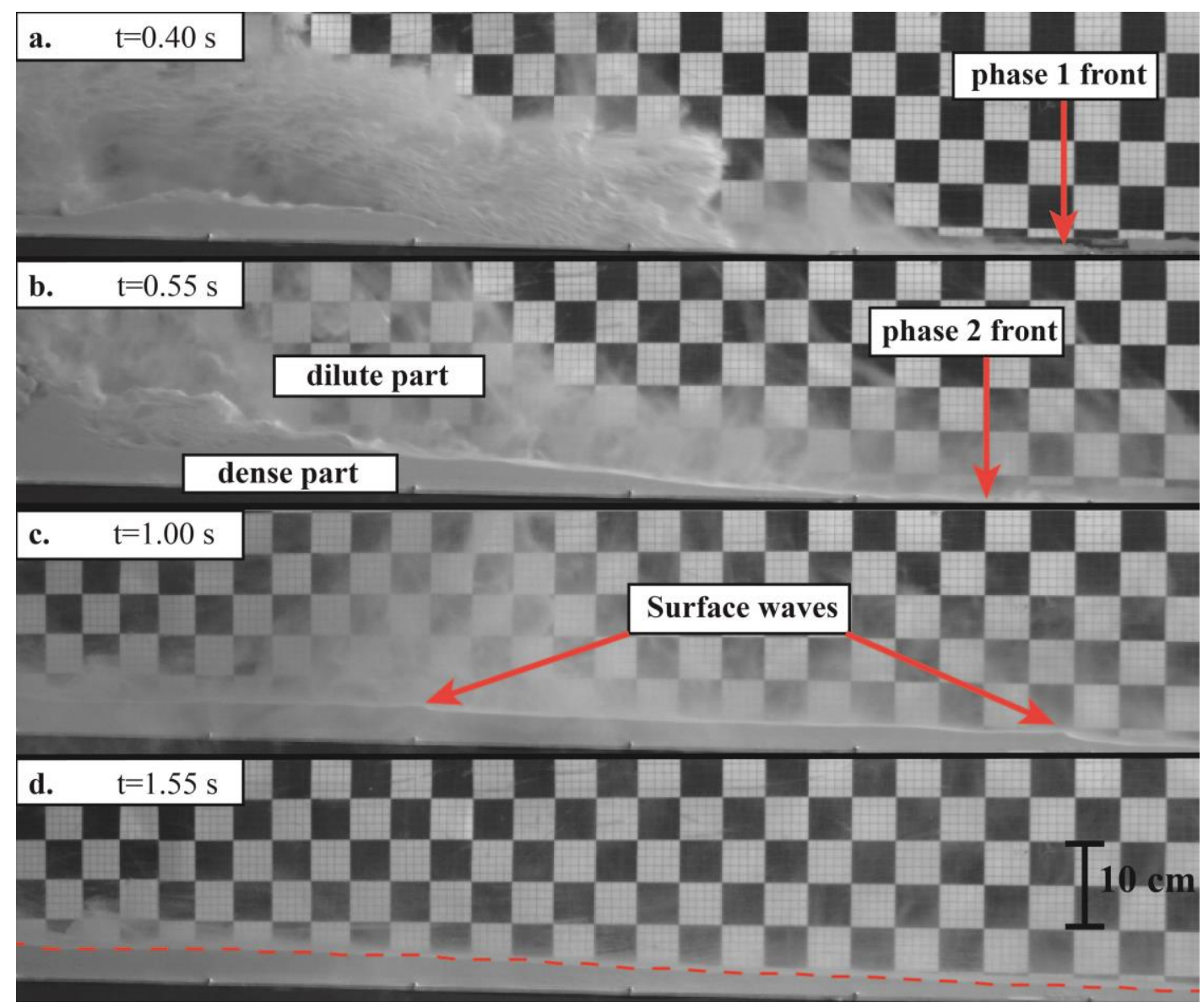

Figure 8. Flow emplacement in the channel at (a) $t=0.40 \mathrm{~s},(\mathbf{b}) \mathrm{t}=0.55 \mathrm{~s}$, (c) $\mathrm{t}=1.00 \mathrm{~s}$, and (d) $\mathrm{t}=1.55 \mathrm{~s}$ during experiment $12(H=2.95 \mathrm{~m}$; Table 1$)$. Panels $\mathrm{a}, \mathrm{b}$, and c correspond to phases 1 (fast-moving thin flow), 2 (slower pulsatory dense flow) and 3 (thickening of the deposit), respectively. Panel d shows the final deposit. 


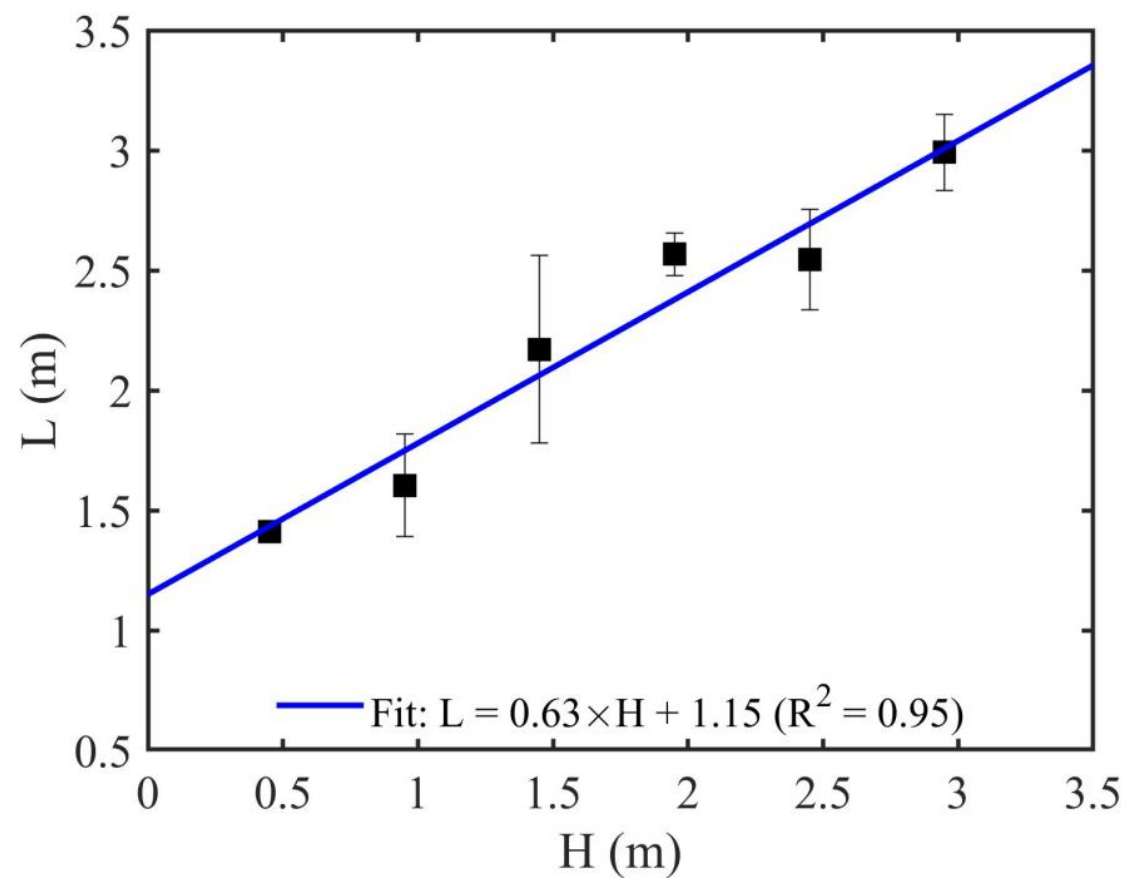

Figure 9. Maximum runout distance $L$ of the flows as a function of the fall height $H$ (solid symbols). The blue line shows the linear best fit of the data. Error bars account for runout variations among the 7 repeats that were possibly caused by particles ejected above the channel walls during flow emplacement and the generation of more vigorous and voluminous spray of particles at impact (i.e. phase 1), respectively. 

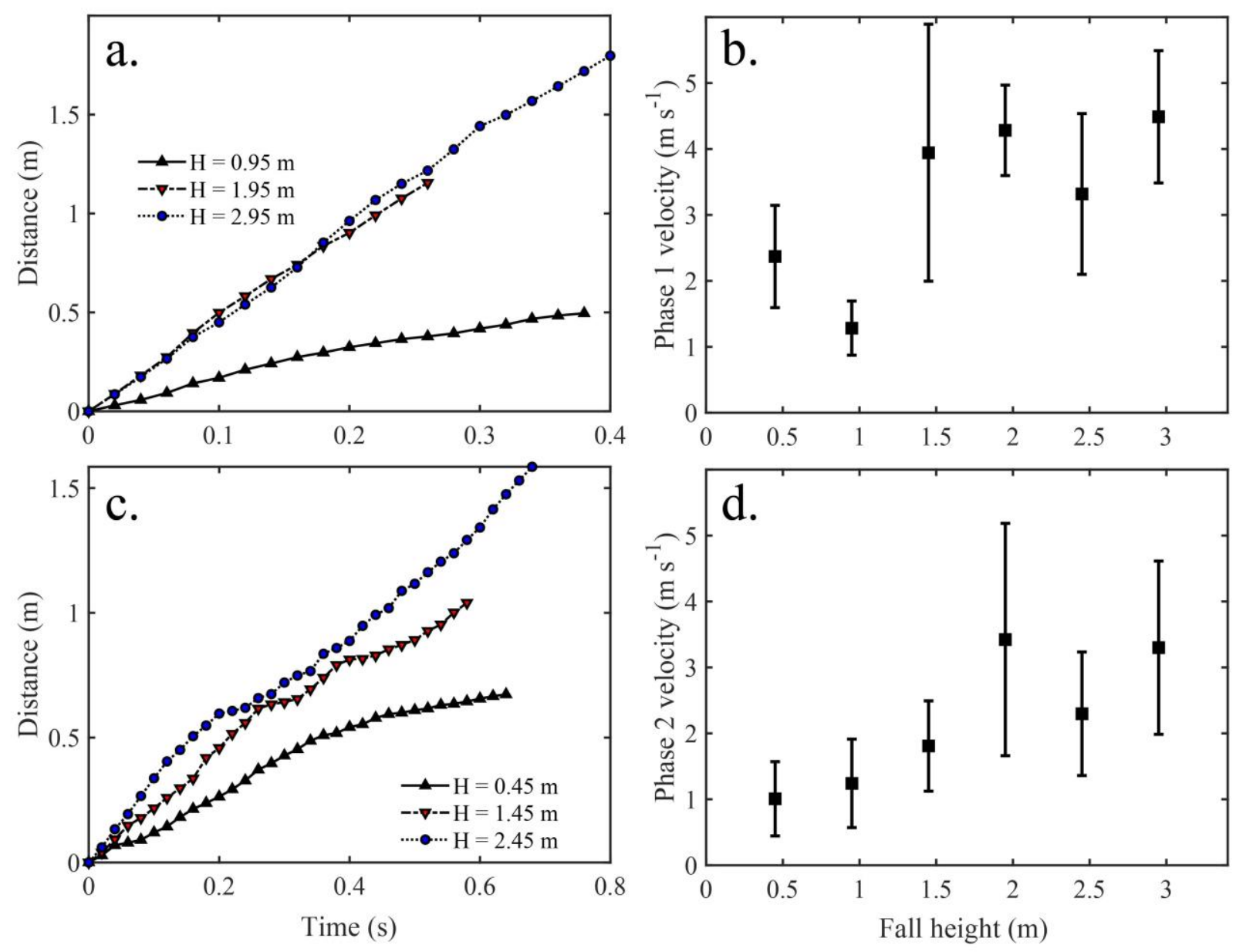

Figure 10. Flow kinematics and mean front velocity as a function of the fall height during phase 1 (a., b.) and phase 2 (c., d.). Note that phase 1 flow is out of the video frame after $0.28 \mathrm{~s}$ for $H$ $=1.95 \mathrm{~m}$ and that no data were collected after that time. 

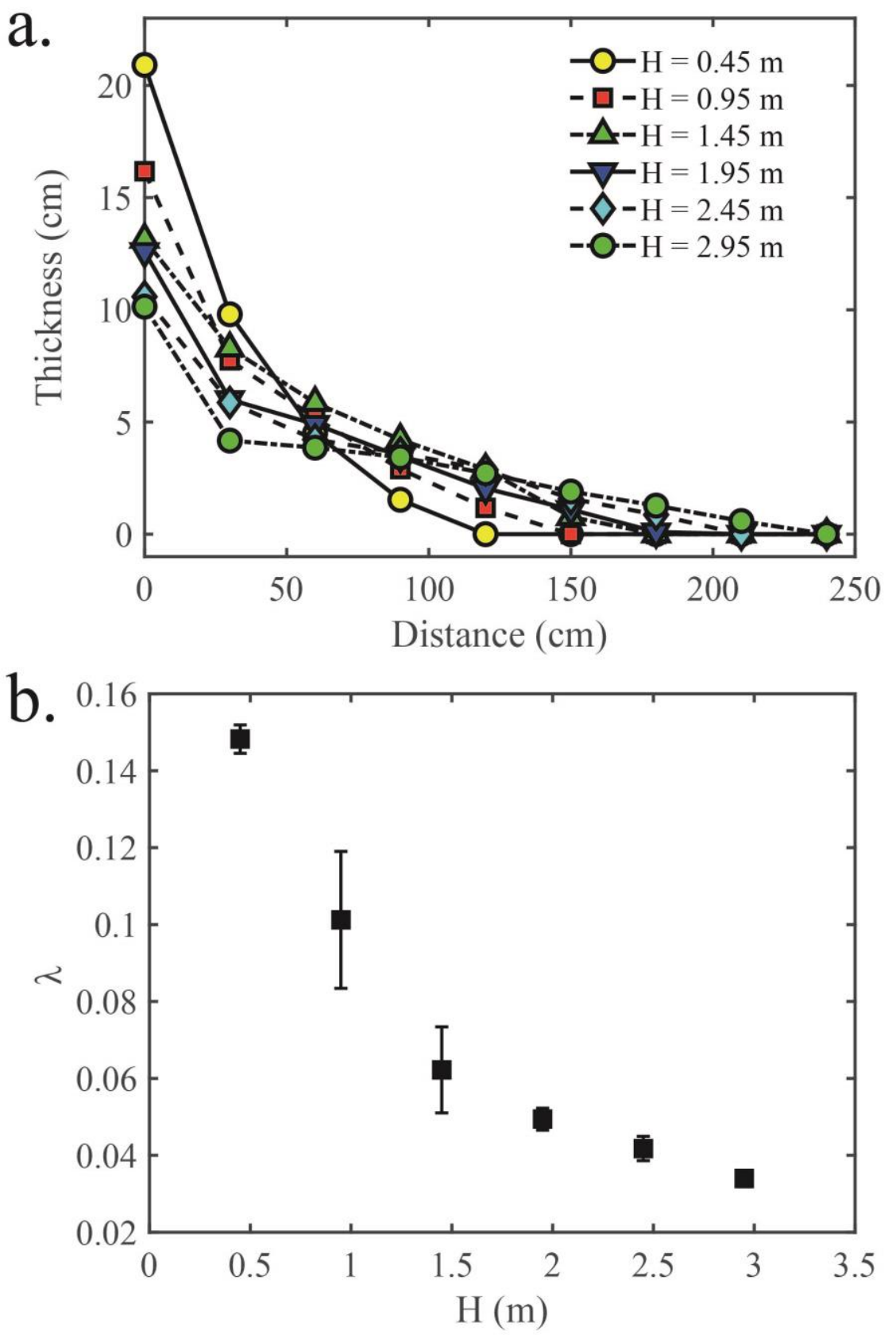

Figure 11. a. Deposit morphology at six different fall heights. b. Deposit aspect ratio $\lambda$ as function of the fall height. 


\section{Supplementary material}


Figure S1. Thickness of the granular material (solid black line) at the impact zone and maximum estimate of the lithostatic pressure for $C=0.46$ vol. \% (red dashed line $P_{L}$ ) as a function of time. Results are shown for fall heights $H=0.45-2.95 \mathrm{~m}$. 


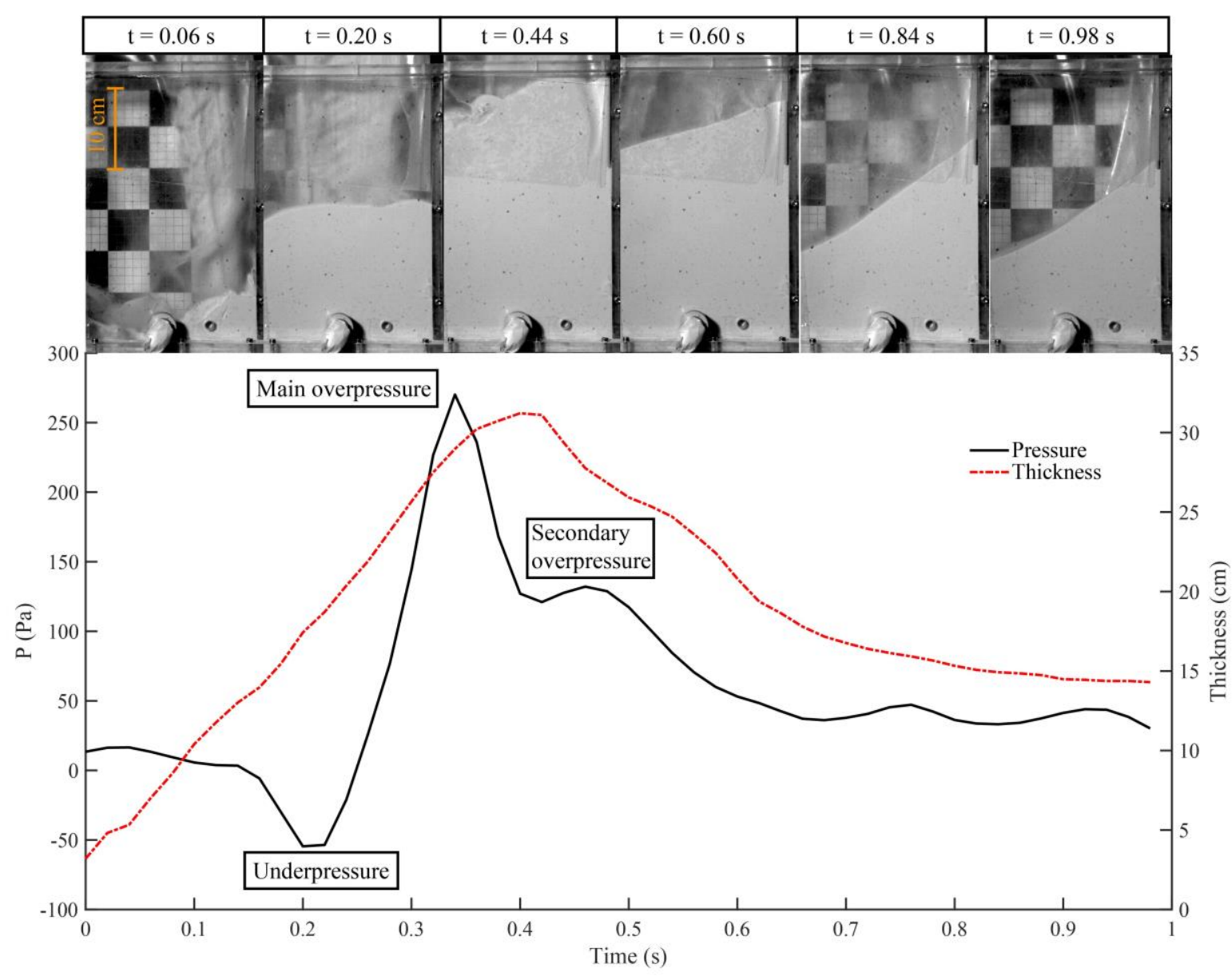

Figure S2. Pore fluid pressure (P; solid black line) and thickness of the granular material (dashdotted red line) as a function of time for an experiment with an initial underpressure phase (experiment 3; $H=0.45 \mathrm{~m}$; Table 1). Images of the impact zone are synchronized with the pressure signal and show the accumulation of the granular mixture. 

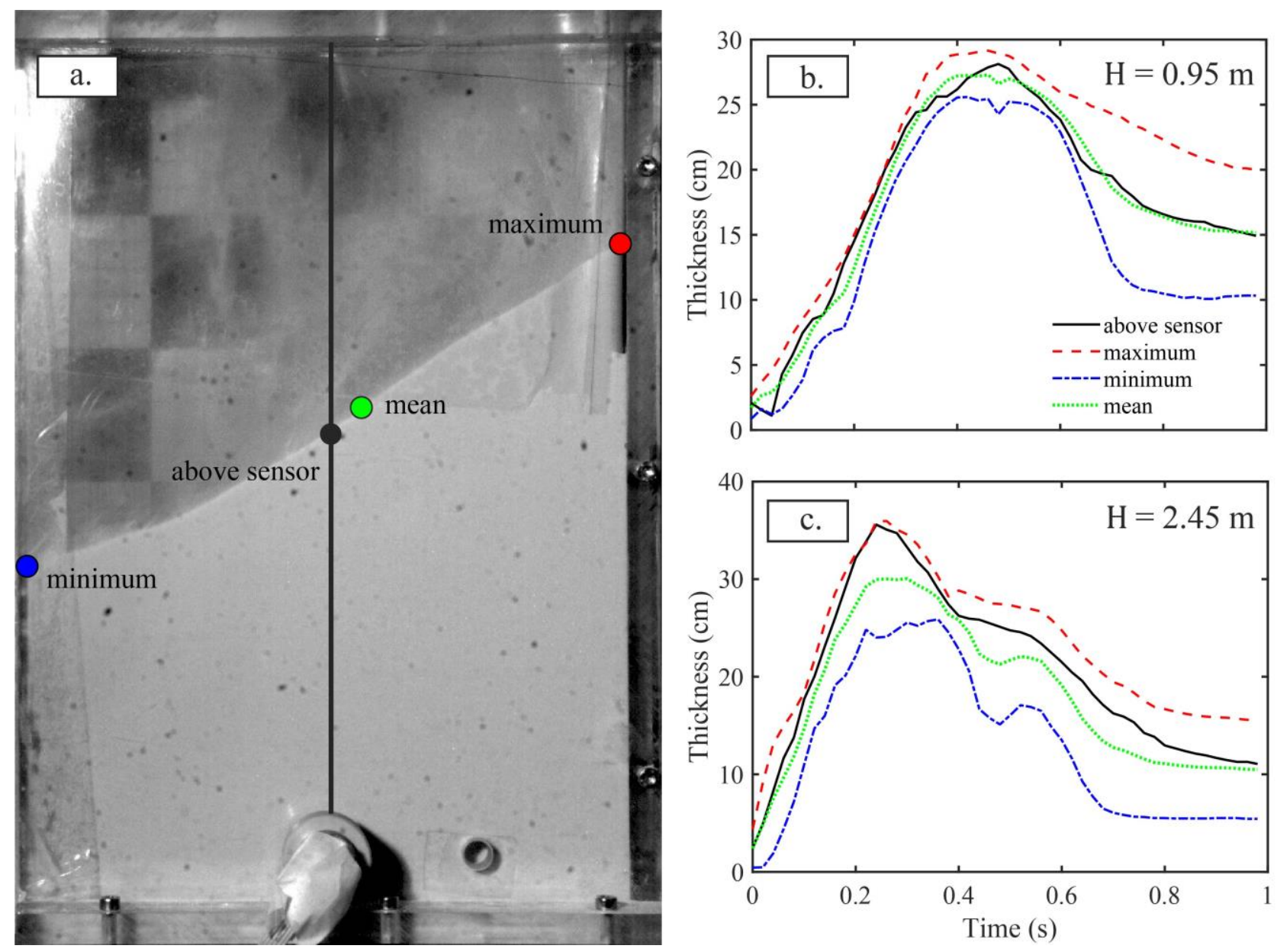

Figure S3. Thickness of the granular material measured at different locations in the impact zone shown in panel (a). (b) Experiment 3, $H=0.95 \mathrm{~m}$. (c) Experiment 9, $H=2.45 \mathrm{~m}$. The granular bed varies significantly in thickness. The lithostatic pressure is calculated considering the bed thickness above the sensor, which is very close to the mean thickness. 


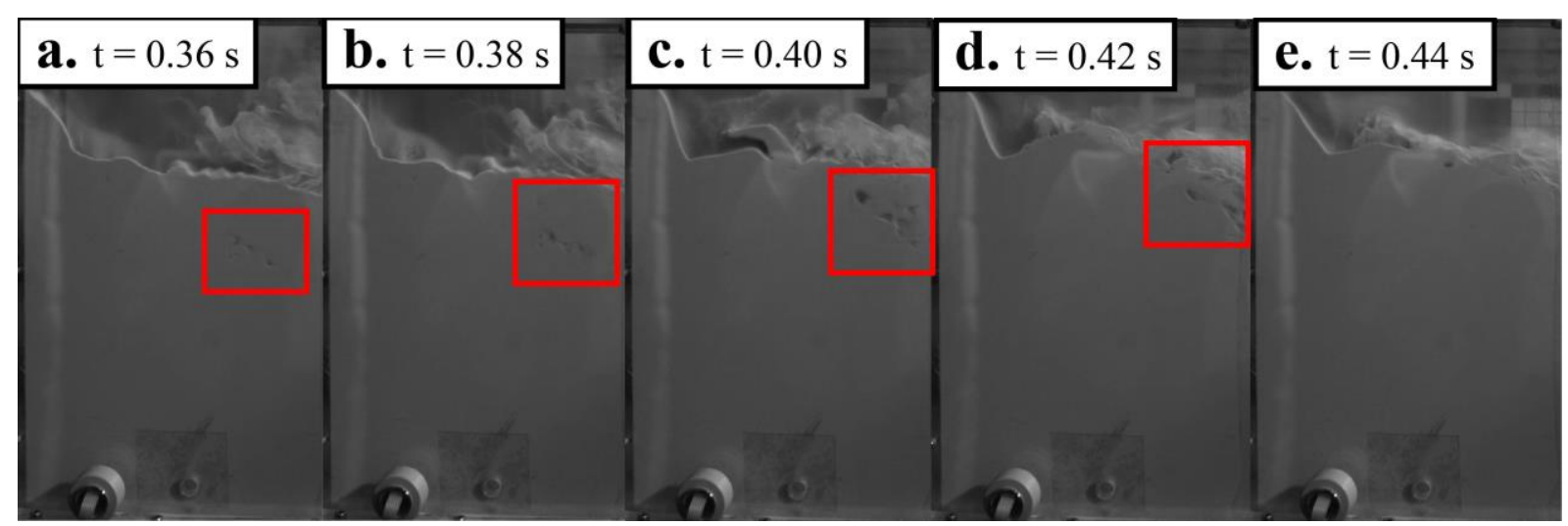

Figure S4. Air bubbles formed during compaction of the granular material at impact zone (experiment 9; Table 1). 


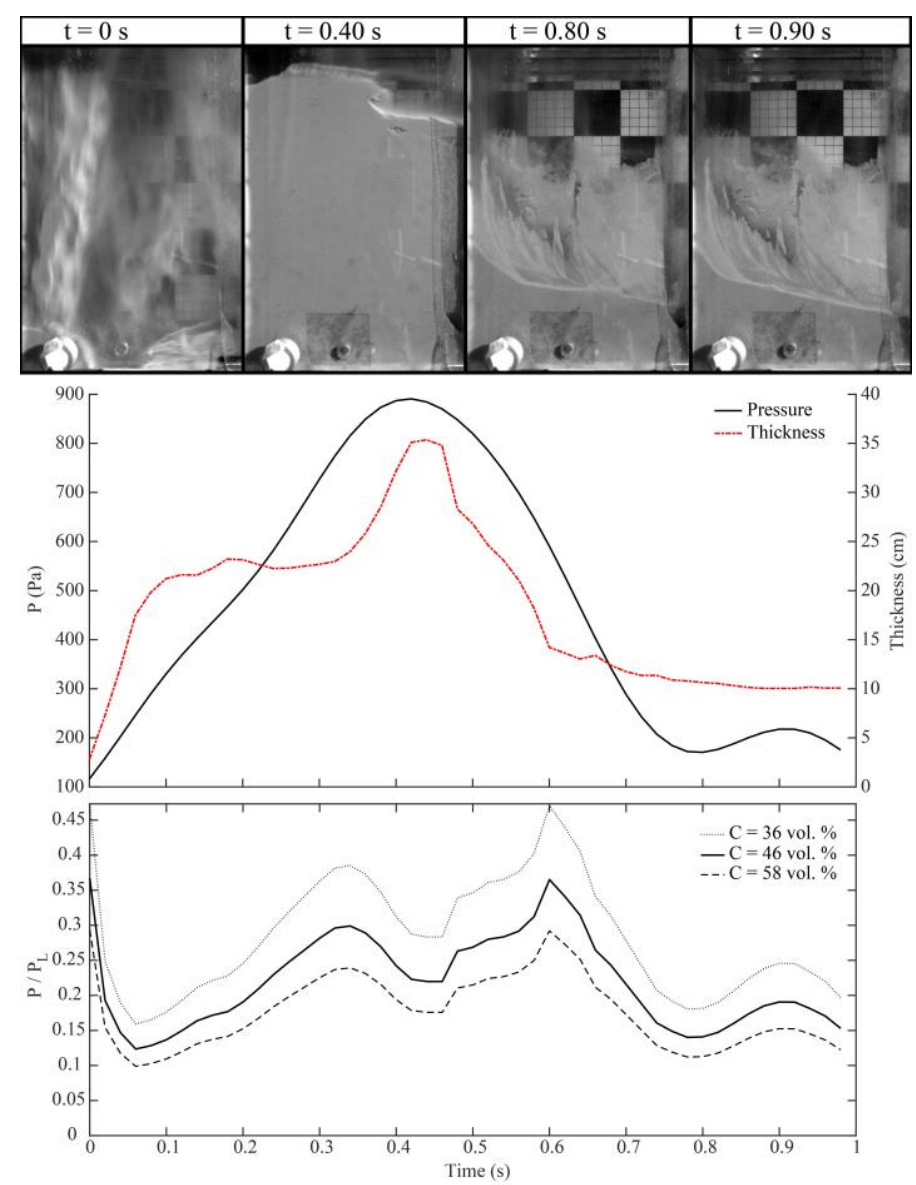

Figure S5. Evolution of $P / P_{L}$ for experiment $11(H=2.95 \mathrm{~m}$; Table 1), considering different values of the particle concentration in the dense granular bed: $C=36 \mathrm{vol}$. $\%$, which is the maximum concentration in the column, $C=46$ vol. $\%$, typical of a bubbling granular bed, and $C=58$ vol. $\%$ for a random packing. 
a. $\quad$ Experiment $1(\mathrm{H}=0.45 \mathrm{~m})$

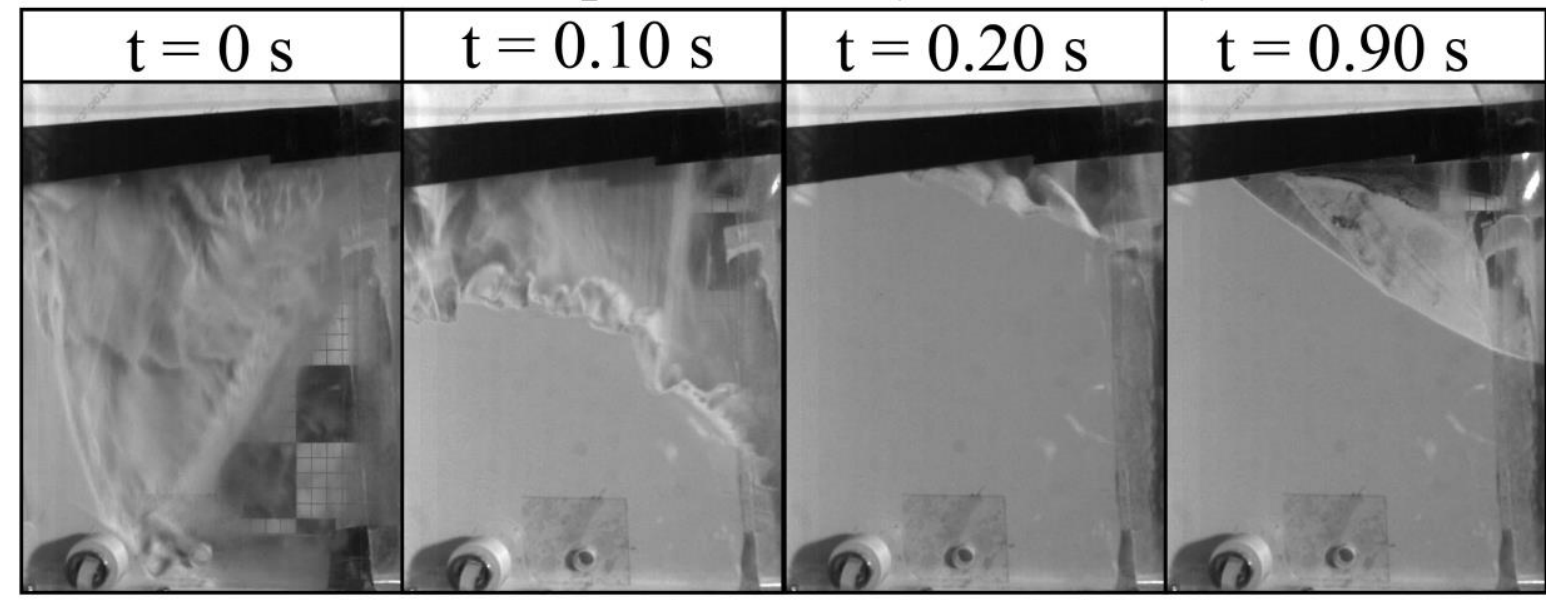

b. $\quad$ Experiment $5(\mathrm{H}=1.45 \mathrm{~m})$

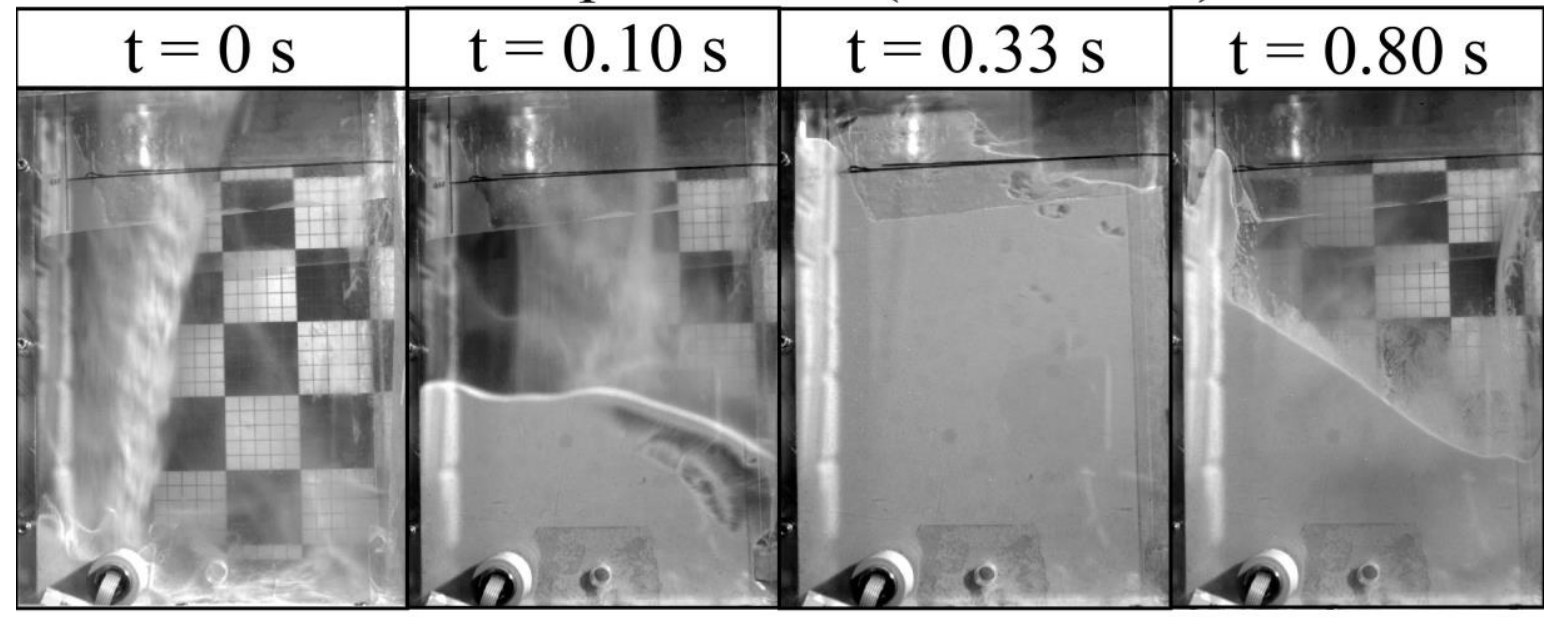

c. $\quad$ Experiment $9(\mathrm{H}=2.45 \mathrm{~m})$

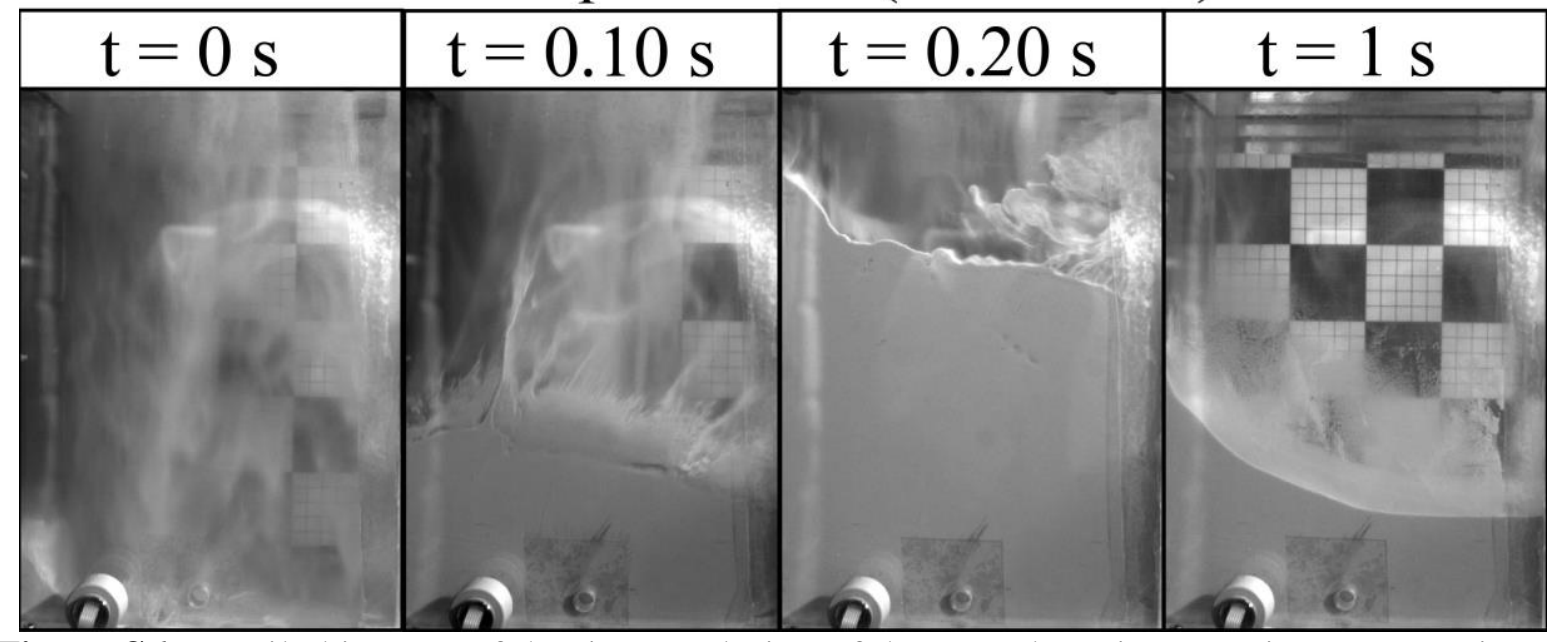

Figure S6. Detailed images of the time evolution of the granular mixture at impact zone in a. experiment $1(H=0.45 \mathrm{~m})$, b. experiment $5(H=1.45 \mathrm{~m})$, and c. experiment $9(H=2.45 \mathrm{~m})$. These high-resolution images are the same as those presented in Figure 7 of the main text. 